\title{
Gas-particle interactions above a Dutch heathland: III. Modelling the influence of the $\mathrm{NH}_{3}-\mathrm{HNO}_{3}-\mathrm{NH}_{4} \mathrm{NO}_{3}$ equilibrium on size-segregated particle fluxes
}

\author{
E. Nemitz and M. A. Sutton \\ Atmospheric Sciences, Centre for Ecology and Hydrology (CEH), Edinburgh Research Station, Bush Estate, Penicuik, \\ Midlothian, EH26 0QB, UK
}

Received: 15 December 2003 - Published in Atmos. Chem. Phys. Discuss.: 15 March 2004

Revised: 11 June 2004 - Accepted: 14 June 2004 - Published: 2 July 2004

\begin{abstract}
Micrometeorological measurements of sizesegregated particle number fluxes above Dutch heathlands and forests have repeatedly shown simultaneous apparent emission of particles with a diameter $\left(D_{\mathrm{p}}\right)<0.18 \mu \mathrm{m}$ and deposition of larger particles when measured with optical particle counters. In order to assess whether this observation may be explained by the equilibrium reaction of ammonia $\left(\mathrm{NH}_{3}\right)$, nitric acid $\left(\mathrm{HNO}_{3}\right)$ and ammonium $\left(\mathrm{NH}_{4}^{+}\right)$, a new numerical model is developed to predict the vertical concentration and flux profiles of the different species as modified by the interaction of equilibration and surface/atmosphere exchange processes. In addition to former studies, the new approach explicitly models the height-dependence of the $\mathrm{NH}_{4}^{+}$ and total aerosol size-distribution. Using this model, it is demonstrated that both gas-to-particle conversion (gtpc) and aerosol evaporation can significantly alter the apparent surface exchange fluxes, and evoke the observed bi-directional particle fluxes under certain conditions. Thus, in general, the $\mathrm{NH}_{3}-\mathrm{HNO}_{3}-\mathrm{NH}_{4} \mathrm{NO}_{3}$ equilibrium needs to be considered when interpreting eddy-covariance particle fluxes. Applied to an extensive dataset of simultaneous flux measurements of particles and gases at Elspeet, NL, the model reproduces the diurnal pattern of the bi-directional exchange well. In agreement with the observation of fast $\mathrm{NH}_{4}^{+}$deposition, slow nitric acid deposition (both as measured by the aerodynamic gradient method) and small concentration products of $\mathrm{NH}_{3} \times \mathrm{HNO}_{3}$ at this site, this study suggests that $\mathrm{NH}_{4}^{+}$evaporation at this site significantly alters surface exchange fluxes.
\end{abstract}

Correspondence to: E. Nemitz

(en@ceh.ac.uk)

\section{Introduction}

Current parameterizations of particle deposition velocity $\left(V_{\mathrm{ds}}\left(R_{\mathrm{p}}\right)\right)$ as a function of particle radius $\left(R_{\mathrm{p}}\right)$ are highly uncertain, with recent field measurements (cf. review by Gallagher et al., 1997) tending to larger values than predicted by theoretical models (Slinn, 1982) and observed during wind tunnel studies (Chamberlain, 1966). In addition, particles frequently show apparent upward fluxes (cf. review by Gallagher et al., 1997). Whilst emissions of super-micron particles have been attributed to wind-driven resuspension (e.g. Nemitz et al., 2002), for smaller particles they can only be explained by alterations due to i) particle nucleation, ii) particle growth or iii) particle evaporation. It has been shown that water vapour gradients can induce size-dependent measurement artefacts as particles loose or take up water during the deposition process (Fairall, 1984; Kowalski, 2001). An alternative growth process is the condensation of the atmospheric gases ammonia $\left(\mathrm{NH}_{3}\right)$ and nitric acid $\left(\mathrm{HNO}_{3}\right)$ on the surface of existing particles to form ammonium nitrate $\left(\mathrm{NH}_{4} \mathrm{NO}_{3}\right)$ aerosol, while volatilization of $\mathrm{NH}_{3}$ and $\mathrm{HNO}_{3}$ from existing $\mathrm{NH}_{4} \mathrm{NO}_{3}$ aerosol particles provides an important mechanism for aerosol evaporation. Here, both process, gas-to-particle conversion (gtpc) and aerosol evaporation, are jointly referred to as "gas-particle interconversion" (gpic).

Several observations of unexpected surface exchange fluxes of $\mathrm{NO}_{3}^{-}, \mathrm{NH}_{4}^{+}$and $\mathrm{HNO}_{3}$ have been attributed to this equilibrium reaction and reproduced with numerical models that calculate the height-dependence of the surface exchange fluxes altered by the chemical production or destruction in the atmosphere: Huebert et al. (1988) observed limited deposition and even emission of $\mathrm{HNO}_{3}$ which Brost et al. (1988) could successfully reproduce. An alternative 


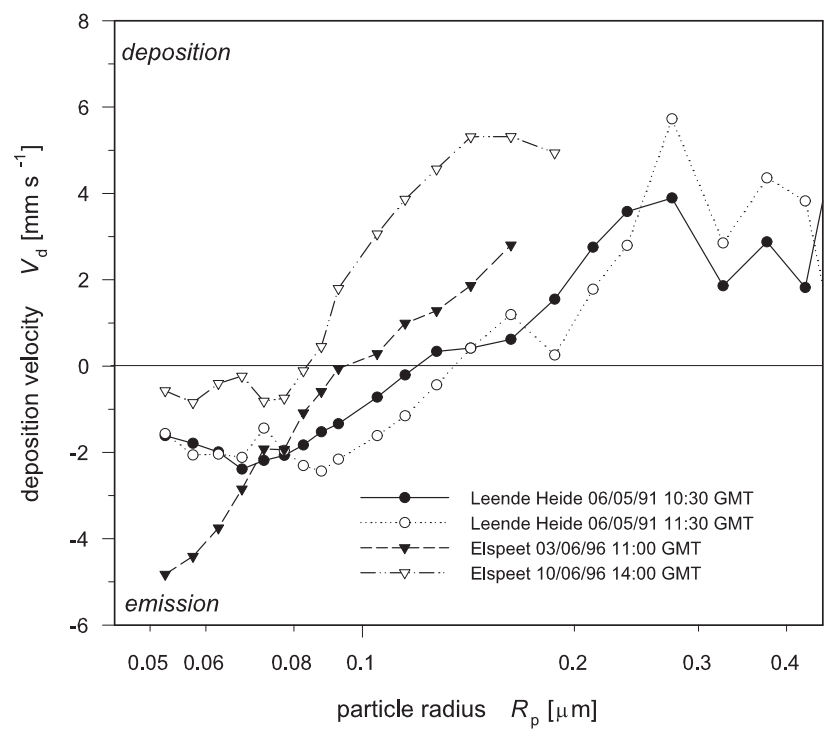

Fig. 1. Particle deposition velocities $\left(V_{\mathrm{d}}\right)$ as a function of particle radius $\left(R_{\mathrm{p}}\right)$ for several example measurement periods derived from eddy-correlation flux measurements above Dutch heathlands at Leende Heide (data taken from Gallagher et al., 1993) and Elspeetsche Veld (Nemitz et al., 2004b).

model was presented by Kramm and Dlugi (1994), which was tied in with an inferential modelling approach of surface exchange. Nemitz et al. (1996) demonstrated that aerosol formation could be the reason for $\mathrm{NH}_{4}^{+}$emission gradients observed above pasture in 1989 at Halvergate, Norfolk, UK (Sutton et al., 1989, personal communication). Van Oss et al. (1998) suggested that the opposite reaction, evaporation of $\mathrm{NH}_{4} \mathrm{NO}_{3}$ aerosol, would explain observations of $\mathrm{NO}_{3}^{-}$ deposition faster than permitted by turbulence (Wyers and Duyzer, 1997), while $\mathrm{NH}_{4} \mathrm{NO}_{3}$ evaporation has repeatedly been stated as a possible explanation of apparent $\mathrm{NH}_{3}$ emission from semi-natural vegetation (Andersen et al., 1999; Pryor et al., 2001; Rattray and Sievering, 2001).

During the reaction of $\mathrm{NH}_{3}$ with $\mathrm{HNO}_{3}$ and $\mathrm{HCl}$ or evaporation of $\mathrm{NH}_{4}^{+}$aerosol, the mass of total ammonium (TA) remains conserved, if other parallel reaction involving $\mathrm{NH}_{3} / \mathrm{NH}_{4}^{+}$can be ignored (Kramm and Dlugi, 1994). Thus the (absolute) divergence of the $\mathrm{NH}_{4}^{+}$flux is of the same magnitude, but of the opposite sign, as the flux divergence of $\mathrm{NH}_{3}$. As $\mathrm{NH}_{4}^{+}$aerosol is usually exchanged with vegetation at a significantly lower rate than $\mathrm{NH}_{3}$, the relative difference between the $\mathrm{NH}_{4}^{+}$flux at the surface and the flux at the measurement height ( $\left.z_{\text {meas }}\right)$ is often larger than for $\mathrm{NH}_{3}$. In particular, gpic is more likely to result in flux reversal of bulk $\mathrm{NH}_{4}^{+}$, as observed at Halvergate (Nemitz et al., 1996; Nemitz, 1998), than in flux reversal of $\mathrm{NH}_{3}$ (e.g. suggested by van Oss et al., 1998).

Whilst numerical modelling activities have been successful in reproducing bulk concentration profiles, measurements of size-segregated fluxes sometimes reveal apparent particle emissions that were restricted to a certain size range. For example, from measurements over heathland (Leende Heide, NL), Gallagher et al. (1993) found a correlation between the occurrence of apparent upward fluxes of small particles and periods of $\mathrm{NH}_{3}$ emission, while larger particles $\left(R_{\mathrm{p}}>0.12 \mu \mathrm{m}\right)$ continuously showed deposition (Fig. 1). The same observation, simultaneous emission of very small and deposition of larger particles, was reported for measurements above a Dutch forest (Gallagher et al., 1997).

The effects of gpic on surface exchange fluxes were addressed by a measurement campaign over heathland near Elspeet, NL (Nemitz et al., 2004a, 2004b). This experiment formed part of the EC "EXAMINE" project (EXchange of AMmonia IN Europe)(Sutton et al., 1996). The measurements at Elspeet also showed prolonged periods of small particle emissions $\left(R_{\mathrm{p}}<0.1 \mu \mathrm{m}\right)($ Nemitz et al., 2004b) as shown in Fig. 1. At the same time, deposition was observed for larger particles, while atmospheric acids $\left(\mathrm{HNO}_{3}, \mathrm{HCl}\right)$ showed a large surface uptake resistance and $\mathrm{NH}_{3}$ was periodically emitted (Nemitz et al., 2004a). By contrast, simultaneous measurements of total aerosol $\mathrm{NH}_{4}^{+}$gradients tended to show deposition velocities that appeared to be too large (Nemitz et al., 2004b).

We here show that the observations of simultaneous bidirectional particle fluxes, as observed at Elspeet and Leende, can be attributed to the chemistry of the $\mathrm{NH}_{3}-\mathrm{HNO}_{3}-$ $\mathrm{NH}_{4} \mathrm{NO}_{3}$ system. This is done by developing a new numerical model for a modified gradient technique that explicitly calculates the particle size-distribution of the $\mathrm{NH}_{4}^{+}$aerosol as a function of height, in addition to the concentration and flux profiles of the bulk aerosol species. From the change of the size-distribution with height $(z)$ apparent deposition velocities $\left(V_{\mathrm{ds} \text {,mod }}\left(R_{\mathrm{p}}, z\right)\right)$ can be inferred, which may be compared with $V_{\mathrm{ds}}$ derived from eddy-covariance (EC) measurements, e.g. using optical particle counters. With the knowledge of the size-distribution it becomes also possible to calculate the chemical time-scale $\left(\tau_{\mathrm{c}}\right)$ of the equilibration process (Wexler and Seinfeld, 1990, 1992) as a function of the size-distribution at each height.

A description of the model is followed by predictions of model results from theoretical considerations, with the model then applied to simplified hypothetical situations. Finally, the conditions during the Elspeet campaign are modelled to investigate and quantify the extent to which the observed emission of fine particles could be explained by either gasto-particle conversion from $\mathrm{NH}_{3}$ and $\mathrm{HNO}_{3}$ or by the evaporation of $\mathrm{NH}_{4}^{+}$containing aerosol. 


\section{Theory: model description}

\subsection{Model description for $\mathrm{NH}_{3}$ and $\mathrm{HNO}_{3}$}

The model description for the gases $\mathrm{NH}_{3}$ and $\mathrm{HNO}_{3}$ is virtually identical to the 1-D model treating bulk $\mathrm{NH}_{4} \mathrm{NO}_{3}$ which was first presented by Brost et al. (1988) and that has, with alterations, been used by other authors (Kramm and Dlugi, 1994; Nemitz et al., 1996; Van Oss et al., 1998): the flux profiles $\left(\mathrm{d} F_{j} / \mathrm{d} z\right)$ are defined by the chemical source terms $\left(Q_{j}\right)$ expressed as first-order relaxation towards equilibrium:

$\frac{\mathrm{d} F_{i}}{\mathrm{~d} z}=Q_{i}=\frac{\left(\chi_{\mathrm{eq}, i}-\chi_{i}\right)}{\tau_{\mathrm{c}}}$,

with $\chi_{j}$ and $\chi_{\mathrm{eq}, j}$ the actual concentration of chemical species $j$ and theoretical concentration at thermodynamic equilibrium, respectively. Naturally, $\bar{\chi}_{\mathrm{NH}_{4} \mathrm{NO}_{3} \text {,eq }}$ is zero if the concentration product of total ammonium $\left(T A=\chi \mathrm{NH}_{3}+\chi \mathrm{NH}_{4} \mathrm{NO}_{3}\right)$ and total nitrate $\left(T N=\chi_{\mathrm{HNO}_{3}}+\chi_{\mathrm{NH}_{4} \mathrm{NO}_{3}}\right)$ is below the dissociation constant $\left(T A \times T N<K_{\mathrm{e}}\right)$ and otherwise it can be calculated from the actual concentrations at a given height according to (e.g. Brost et al., 1988):

$$
\bar{\chi}_{\mathrm{NH}_{4} \mathrm{NO}_{3} \mathrm{eq}}=0.5\left(T N+T A-\sqrt{(T N+T A)^{2}-4\left(T N \times T A-K_{\mathrm{e}}\right)}\right) .
$$

Here $K_{\mathrm{e}}$ of $\mathrm{NH}_{4} \mathrm{NO}_{3}$ is a function of temperature $(T)$, humidity $(h)$ (Mozurkewich, 1993) and particle composition. (First-order) closure is provided by the classical flux-gradient relationship for inert tracers (Kramm and Dlugi, 1994):

$$
F_{j}=-K_{\mathrm{H}}\left(\frac{z}{L}\right) \frac{\mathrm{d} \chi_{i}}{\mathrm{~d} z} ; \quad K_{\mathrm{H}}=\frac{\kappa u_{*} z}{\phi_{\mathrm{H}}\left(\frac{z}{L}\right)},
$$

where $z$ is height above the zero-plane displacement $(d)$, $K_{\mathrm{H}}$ is the eddy-diffusivity of inert scalars, $L$ is the MoninObukhov stability length, $\kappa$ is the von Karman constant (0.41), $u_{*}$ the friction velocity and $\phi_{\mathrm{H}}$ is a stability correction function (e.g. Thom, 1975). Although $K_{\mathrm{H}}$ is modified by the reaction (e.g. Galmarini et al., 1997), the use of $K_{\mathrm{H}}$ for inert tracers was estimated to be sufficiently accurate over the lowest few metres of the surface-layer (Nemitz, 1998). Based on the mass transport theory of Schwartz and Freiberg (1981), the chemical time-scale $\left(\tau_{\mathrm{c}}\right)$ is approximated by the timescale for equilibrium due to changes in the background gasphase concentrations $\left(\tau_{\infty}\right)$. This time-scale can be calculated from the size-distribution of the estimated hydrophilic aerosol, which in the present model is predicted as a function of height (Wexler and Seinfeld, 1990):

$$
\tau_{\mathrm{c}}^{-1} \approx \tau_{\infty}^{-1}=3 \bar{D} \sum_{i} \frac{m_{i}}{\left(1+\beta_{i}\right) R_{\mathrm{p}, i}^{2} \rho_{\mathrm{p}, i}} ; \quad \beta_{i} \approx \frac{0.065 \mu \mathrm{m}}{\alpha R_{\mathrm{p}, i}} .
$$

Here $m_{i}$ is the mass, $R_{\mathrm{p}, i}$ the particle radius, $\rho_{p, i}$ the density and $\beta_{i}$ the accommodation factor of particles in size class $i$. $\alpha$ is the sticking coefficient and $\bar{D}$ is the geometric mean of the diffusivities of $\mathrm{NH}_{3}$ and $\mathrm{HNO}_{3}$.

\subsection{Model layout for size-distributed $\mathrm{NH}_{4} \mathrm{NO}_{3}$}

Equations (1) and (3) for the three chemical species $\left(j=\mathrm{NH}_{3}\right.$, $\mathrm{HNO}_{3}, \mathrm{NH}_{4} \mathrm{NO}_{3}$ ) form a system of 6 coupled first-order differential equations that may be solved numerically. The height-dependence of the $\mathrm{NH}_{4}^{+}$aerosol size spectrum as modified by the surface exchange fluxes and the equilibration does not appear to have been modelled above the canopy before. Consequently, a new set of equations is developed here. To make the problem tractable the following assumptions are made:

a) Hydrophilic and hydrophobic aerosols are assumed to be externally mixed (Wexler and Seinfeld, 1992). Condensation of the vapour phase takes place only to hydrophilic aerosol, and this is approximated by the sum of the measured major ionic species $\left(\mathrm{NO}_{3}^{-}, \mathrm{Cl}^{-}, \mathrm{SO}_{4}^{2-}\right.$, $\mathrm{NH}_{4}^{+}, \mathrm{Na}^{+}, \mathrm{Mg}^{2+}$ and $\mathrm{Ca}^{2+}$ ). Any organic (hydrophobic) aerosol is considered to be chemically inactive and deposit at the rate $V_{\mathrm{ds} \text {,inert }}$.

b) Within each size class, all hydrophilic aerosol particles are of identical composition.

c) Only the reaction of $\mathrm{NH}_{3}$ with $\mathrm{HNO}_{3}$ forming $\mathrm{NH}_{4} \mathrm{NO}_{3}$ aerosol is considered. The model is constructed so as to allow the interaction with $\mathrm{HCl}$ to be included at a later stage.

d) The density of all particles $\left(\rho_{\mathrm{p}}\right)$ is the same and does not change during the evaporation/formation of $\mathrm{NH}_{4} \mathrm{NO}_{3}$. Consistent with this assumption, $\rho_{\mathrm{p}}$ is set to the value for $\mathrm{NH}_{4} \mathrm{NO}_{3}\left(\rho_{\mathrm{p}}=1.7 \mathrm{~g} \mathrm{~cm}^{-3}\right)$.

e) All particles are assumed to be spherical.

f) For the size-range under consideration, the effects of coagulation (estimated from Seinfeld and Pandis, 1997) and hygroscopic growth associated with relative humidity $(h)$ gradients are generally assumed to be negligible compared with growth caused by condensation of $\mathrm{NH}_{3}$ and $\mathrm{HNO}_{3}$, although there may be situations where $h$ gradients have a significant effect.

g) New particle formation is ignored. This simplification is justified for the Netherlands, where the aerosol surface area is large, and the time-scale of diffusive transport of the gases to the aerosol therefore small compared with the time-scale of nucleation.

h) $\tau_{\mathrm{c}}$ is composed of two time-scales, describing the attainment of equilibrium due to changes in the background concentrations of the precursor gases $\left(\tau_{\infty}\right)$ and due to changes in the partial pressures at the particle surface $\left(\tau_{\mathrm{d}}\right) . \tau_{\mathrm{d}}$ may be small close to the deliquescence point, but at present there is no approach to estimate $\tau_{\mathrm{d}}$ for a heterogeneous particle assembly (Wexler and Seinfeld, 1992). 
As with the model for the bulk species, the height-range between the surface $\left(z_{0}\right)$ and a reference height $\left(z_{\text {ref }}\right)$ is divided into $h_{\max }$ logarithmically spaced layers, such that $z_{1}=z_{0}$ and $z_{h_{\max }}=z_{\text {ref }}$ (see Appendix A). At $z_{\text {ref }}$ the aerosol is divided into $i_{\max }$ size sections (bins) of logarithmically spaced medium particle radii $\left(R_{i h}, i=1, i_{\max }\right)$, which change with height due to condensation/evaporation effects. In the following the index $i$ always refers to an aerosol size class and $h$ refers to a height layer.

The concentration of $\mathrm{NH}_{4} \mathrm{NO}_{3}$ in size bin $i$ at height $h$ is $c_{i h}\left[\mathrm{nmol} \mathrm{m}^{-3}\right]$, while the total mass of hydrophilic aerosol is $m_{i h}\left[\mathrm{ng} \mathrm{m}^{-3}\right]$. In order to obtain information about the height-dependent size distribution of the aerosol, it is not sufficient to solve the differential equations for the $c_{i h}$, but the values of $R_{i h}$ have to be calculated explicitly, together with their first and second derivatives with respect to $h$. This is achieved by expressing the concentration for each bin at any height, through $R_{i h}$ and the particle number density $\left(n_{i h}\right)$. Since the condensation of the vapour phase is assumed to take place on the surface of any hydrophilic aerosol, only partly consisting of $\mathrm{NH}_{4} \mathrm{NO}_{3}$, the mass fraction of $\mathrm{NH}_{4} \mathrm{NO}_{3}$ $\left(S_{i h}\right)$ is introduced as:

$S_{i h}=c_{i h} M_{\mathrm{r}, A N} / m_{i h}$,

where $M_{\mathrm{r}, A N}$ is the molecular mass of $\mathrm{NH}_{4} \mathrm{NO}_{3}$ in $\mathrm{g} \mathrm{mol}^{-1}$. Using this concentration ratio, $c_{i h}$ may be expressed as a function of particle number density $\left(n_{i h}\right)$ in $\left[\mathrm{m}^{-3}\right]$ and radius $\left(R_{i h}\right)$ in $(\mu \mathrm{m})$ :

$c_{i h}=k n_{i h} S_{i h} R_{i h}^{3}$

where $k$ is a constant of the value

$k=4 / 3 \pi \rho_{\mathrm{p}} M_{\mathrm{r}, A N}^{-1}$.

It can be shown that for any $h$ the concentration of $\mathrm{NH}_{4} \mathrm{NO}_{3}$ may be written as:

$c_{i h}=k n_{i h}\left[R_{i h}^{3}-y_{i}\right] ; y_{i}=\left(1-S_{\mathrm{ref}, i}\right) R_{\mathrm{ref}, i}^{3}$.

The constants $y_{i}$ are height invariant and the product $k \times y_{i}$ may be identified with the mass fraction of a particle in size bin $i$ that does represent $\mathrm{NH}_{4} \mathrm{NO}_{3}$. In this formulation of $c_{i h}$, $S_{i h}$ does not appear as an independent variable, but has been reduced to the mixing ratio at the reference height $\left(S_{\mathrm{ref}, i}\right)$. Equation (8) also implies that $c_{i h}$ is fully determined by the number density, as well as the radius of the bin, and the calculation of the profiles of $c_{i h}$ can thus be reduced to the problem of solving the profiles of $R_{i h}$ and $n_{i h}$.

As with the model for the bulk species, $R_{i h}$ and $n_{i h}$ need to be solved together with their first and second heightderivatives, which requires $4 \times i_{\max }$ boundary conditions to be prescribed. To prepare the model for the application to measurement data, boundary conditions are provided by:

(i) the logarithmically spaced radii at $z_{\text {ref }}\left(R_{i h_{\max }}\right)$, (ii) the mass distribution at $z_{\text {ref }}, c\left(i h_{\max }\right)$; the $n_{i h_{\max }}$ follow from Eq. (8),

(iii) the parameterization of the particle deposition velocity at the surface $\left(V_{\mathrm{ds} \text {, inert }}\left(R_{i 1}\right)\right)$, from which the derivatives $\mathrm{d} n_{i 1} / \mathrm{d} z$ may be calculated (see below). This parameterization is either taken from field measurements, which appear to be unaffected by gtpc processes (cf. Nemitz et al., 2004b) or from theoretical studies, such as Slinn (1982).

(iv) the description of the derivatives $\mathrm{d} R_{i} / \mathrm{d} z$ at one height. Since the change in the size distribution with height is too subtle to be resolved with typical sizing instruments, the radius can only be prescribed at a single height $\left(z_{\text {ref }}\right)$. Consequently, the second set of boundary conditions for the radii has to concern the height derivative of $R_{i}$. Two different approaches will be discussed below (Sect. 2.6).

\subsection{Calculation of the gradients of the $\mathrm{R}_{i h}$ and $\mathrm{n}_{i h}$}

To calculate $R_{i h}$ and $n_{i h}$ a moving sectional method (e.g. Dhaniyala and Wexler, 1996) is used: particle growth and evaporation are described by the change of the bin radius with height rather than by redistributing particles across the size bins. The advantage of this procedure is its simplification for the calculation of $n_{i h}$ : as the number density within each bin is unaffected by the chemical conversion, the flux of $n_{i h}\left(F_{n_{i}}\right)$ remains constant with height.

An attempt to visualize this four-dimensional problem $(R$ and $n$ as functions of $i$ and $h$ ) is presented in Fig. 2 for a simplified case of 5 height layers and 7 size classes for the case of aerosol growth. Due to the condensation of $\mathrm{NH}_{3}$ and $\mathrm{HNO}_{3}$, the radius characterizing the size class (dash-dotted line) increases towards the ground while the particles deposit. At the same time, surface removal causes the particle numbers (dotted lines), which in this scenario are assumed to be log-normally distributed at the upper reference height, to decrease towards the ground.

Comparing the mass distributions (dashed lines) at the different heights, it becomes apparent that the mass of small particles decreases with increasing height (emission) at the same time as the mass of the large particles increases (deposition).

The removal rate is fully determined by the particle radii at the ground surface. From the gradients of $n_{i h}$ and $R_{i h}$ the concentration distributions $\left(c_{i h}\right.$; dashed lines) at any height follow according to Eq. (8).

The model alternately solves the profiles of $n_{i h}$ and $R_{i h}$ : a generalized shooting algorithm using a 4th-order RungeKutta integrator (e.g. Keller, 1968; Press et al., 1989) is used to solve the second-order differential equations of the $R_{i h}$ together with the bulk concentration profiles of the gases from $z_{\text {ref }}$ down to $z_{0}$. After each iteration step $(q)$, the $n_{i h}$ are calculated analytically from the current value of the radii at the 


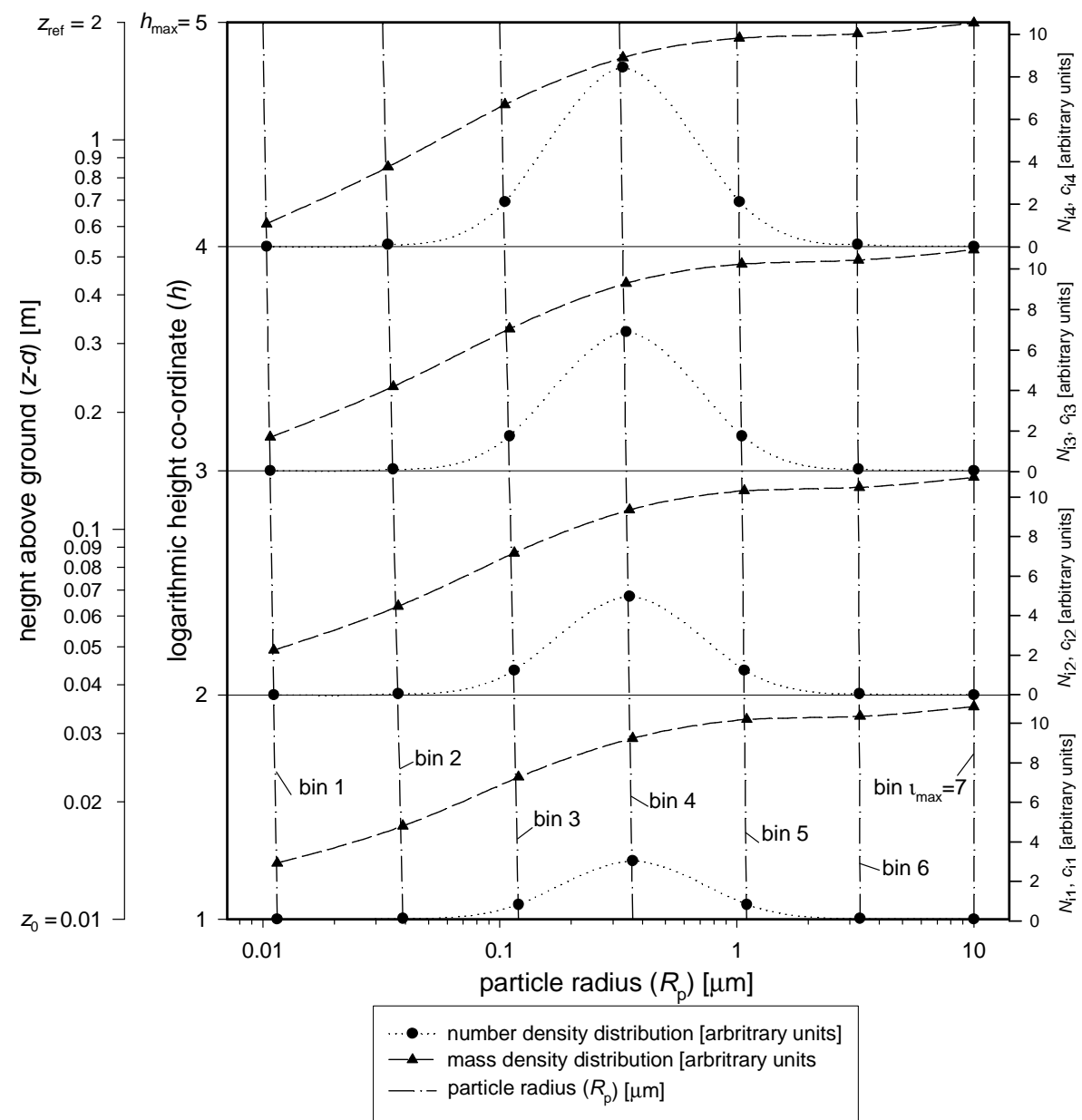

Fig. 2. Schematic of the model set-up for the $\mathrm{NH}_{4} \mathrm{NO}_{3}$ aerosol size bins (exaggerated). The number density, assumed to be log-normally distributed at $z_{\text {ref }}$, decreases towards the ground due to deposition, while the particle radius increases due to condensational growth. In the present case the net effect is an upward gradient of the mass density for small particles and a downward gradient for large particles.

surface $\left(R_{i 1}^{(\mathrm{q})}\right)$ and the chosen parameterization of the deposition velocity $V_{\mathrm{ds} \text {, inert }}\left(R_{i 1}\right)$.

\subsubsection{Differential equation for the $\mathrm{R}_{i h}$}

From Eq. (8) the change of the $\mathrm{NH}_{4} \mathrm{NO}_{3}$ distribution with height $\left(c_{i h}^{\prime}\right)$ can be calculated from the change in the particle number density and the radius:

$c^{\prime}=\frac{\partial c}{\partial R} R^{\prime}+\frac{\partial c}{\partial n} n^{\prime}=3 k n R^{2} R^{\prime}+k\left(R^{3}-y\right) n^{\prime}$,

where the indices $i$ and $h$ have been dropped for reasons of simplicity and the operator represents the total derivative with respect to $h$. The flux of size class $i$ at height $z_{h}\left(F_{c_{i h}}\right)$ is related to $c_{i h}^{\prime}$ by:

$F_{c_{i h}}=-K_{\mathrm{H}}\left(z_{h}\right) \frac{\mathrm{d} c}{\mathrm{~d} z}=-K_{\mathrm{H}}\left(z_{h}\right) \frac{z}{b} c_{i h}^{\prime}$,

where $b$ is defined in Appendix A. From Eqs. (8) and (9) the following expression for the second derivative of the radius with respect to the logarithmic height variable $h$ can be derived (see Appendix A):

$$
\begin{aligned}
R^{\prime \prime} & =\frac{1}{3}\left[-6 \frac{R^{\prime} n^{\prime}}{n}-6 \frac{R^{\prime 2}}{R}+\frac{3 R^{\prime}}{b}\right. \\
& +\left(\frac{n^{\prime}}{b n}-\frac{n^{\prime \prime}}{n}-\frac{K_{\mathrm{H}}^{\prime} n^{\prime}}{K_{\mathrm{H}} n}\right)\left(R-\frac{y}{R^{2}}\right) \\
& \left.-\frac{3 R^{\prime} K_{\mathrm{H}}^{\prime}}{K_{\mathrm{H}}}+\frac{z^{2}\left(c_{\mathrm{tot}, i}-c_{\mathrm{tot}, i, \mathrm{eq}}\right)}{K_{\mathrm{H}} b^{2} k n R^{2} \tau_{\mathrm{c}, i h}}\right]
\end{aligned}
$$

where $c_{\text {tot }}$ is the sum of the $c_{i h}\left(i=1, \ldots, i_{\max }\right)$, and $c_{\text {tot,eq }}$ the concentration at thermodynamic equilibrium (similar to $\chi \mathrm{NH}_{4} \mathrm{NO}_{3, \text { eq }}$ of Eq. 1). Both values are discussed below.

\subsubsection{Analytical calculation of the $\mathrm{n}_{i h}$ and numerical algo- rithm}

Since the particle number flux within each bin is constant with height, the number flux $\left(F_{n_{i}}\right)$ can be calculated 
analytically from classical micrometeorological theory for inert tracers, once the radius at the surface $\left(R_{i 1}\right)$ has been found:

$$
F_{\mathrm{n}_{i}}=-\frac{\mathrm{n}_{i h_{\max }}}{R_{\mathrm{a}}\left(z_{\mathrm{ref}}\right)+V_{\mathrm{ds}, \text { inert }}^{-1}\left(R_{i 1}\right)},
$$

where the aerodynamic resistance $\left(R_{\mathrm{a}}(z)\right)$ can be calculated from (measured) standard micrometeorological parameters (e.g. Garland, 1977). From these the profiles of $n_{i h}, n_{i h}^{\prime}$ and $n_{i h}^{\prime \prime}$ may be derived as:

$n_{i h}=-F_{\mathrm{n}_{i}}\left(R_{\mathrm{a}}\left(z_{h}\right)+V_{\mathrm{ds}, \text { inert }}^{-1}\left(R_{i 1}\right)\right)$

$n_{i h}^{\prime}=-\frac{z_{h}}{b} \frac{F_{\mathrm{n}_{i}}}{K_{\mathrm{H}}\left(z_{h}\right)}$

$n_{i h}^{\prime \prime}=\frac{n_{i h}^{\prime}}{b}-n_{i h}^{\prime} \frac{K_{\mathrm{H}}^{\prime}\left(z_{h}\right)}{K_{\mathrm{H}}\left(z_{h}\right)}$

The overall procedure of calculating the size-resolved gradients of $\mathrm{NH}_{4}^{+}$may be summarized as follows:

1. As an initial guess, all $R_{i 1}$ are set equal to $R_{i h_{\max }}$ and the $R^{\prime}\left(z_{h_{\max }}\right)$ are set to zero.

2. From the boundary values of $n_{i h_{\max }}$ and $V_{\mathrm{ds} \text {, inert }}\left(R_{i 1}\right)$, the $n_{i h}, n_{i h}^{\prime}$ and $n_{i h}^{\prime \prime}$ are calculated according to Eqs. (12) to (15).

3. The $i_{\max }$ differential equations for $R_{i h}$ (Eq. 11) are integrated together with the two sets of differential equations, each composed of Eqs. (1) and (3), for $\mathrm{NH}_{3}$ and $\mathrm{HNO}_{3}$ from $z_{\text {ref }}$ down to $z_{0}$ using a 4th-order RungeKutta algorithm (Press et al., 1989).

4. The integration leads to new values of $R_{i 1}$ and therefore $V_{\mathrm{ds}, \text { inert }}\left(R_{i 1}\right)$ at the surface.

5. New guesses of $R^{\prime}\left({ }_{z} h_{\max }\right)$ are calculated according the Newton-Rhapson method (Keller, 1968).

6. Steps $2-5$ are repeated until a stable solution has been found.

7. From $R_{i h}, R_{i h}^{\prime}, n_{i h}$ and $n_{i h}^{\prime}$ The concentration profiles $\left(c_{i h}\right.$ and $\left.c_{i h}^{\prime}\right)$ and fluxes $\left(F_{c_{i h}}\right)$ may now be calculated using Eqs. (6), (9) and (10), respectively.

\subsection{Thermodynamic module and characteristic time-scale}

The chemical production/destruction terms for each size class $\left(Q_{i}\right)$ are expressed as first-order relaxation towards equilibrium (Eq. 1). To ensure mass conversation and consistency with the model for the bulk species, the sum over the individual $Q_{c_{i}}$ must equal $Q_{\mathrm{NH}_{4} \mathrm{NO}_{3}}$ of the bulk model, i.e.

$$
Q_{\mathrm{NH}_{4} \mathrm{NO}_{3}}=\frac{\chi_{\mathrm{NH}_{4} \mathrm{NO}_{3}}-\chi_{\mathrm{NH}_{4} \mathrm{NO}_{3}, \mathrm{eq}}}{\tau_{\mathrm{c}, \text { bulk }}} \equiv \sum_{i} Q_{c_{i}}=\sum_{i} \frac{c_{\mathrm{tot}, i}-c_{\mathrm{tot}, i, \mathrm{eq}}}{\tau_{\mathrm{c}, i}}
$$

$c_{\text {tot }, i}$ is the total $\mathrm{NH}_{4} \mathrm{NO}_{3}$ concentration and therefore identical to $\chi_{\mathrm{NH}_{4} \mathrm{NO}_{3}}$ for all $i$. By contrast, $c_{\text {tot, } i, \text { eq }}$ represents the equilibrium $\mathrm{NH}_{4} \mathrm{NO}_{3}$ concentration due to the equilibration through condensation or evaporation in size-bin $i$. If the surface vapour pressure is the same for all particles, this value, calculated according to Brost et al. (1988), is identical to the

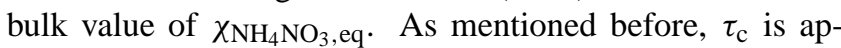
proximated by $\tau_{\infty}$ as described by Eq. (4), in which $m_{i}$ is substituted by $c_{i} \times M_{\mathrm{r}, A N}$. Since in this equation the individual $\tau_{\infty, i}$ add reciprocally to the bulk time-scale, Eq. (16) is automatically fulfilled. However, the vapour pressure above aqueous particles smaller than $0.1 \mu \mathrm{m}$ in radius becomes increasingly elevated by the Kelvin effect, and $K_{\mathrm{e}}$ needs to be multiplied by the Kelvin factor ( $f_{\text {Kelvin }}$ ), leading to slightly modified values of $c_{\text {tot, } i \text {,eq }}$ :

$f_{\text {Kelvin }}=\exp \left(\frac{2 \sigma_{j} v_{j}}{R_{\mathrm{G}} T R_{\mathrm{p}}}\right)$.

Here $\sigma_{j}$ and $v_{j}$ are the surface tension and molar volume of chemical species $j$, respectively (for values cf. Wexler and Seinfeld, 1990), $R_{\mathrm{G}}$ is the universal gas constant and $T$ the absolute temperature in $\mathrm{K}$. In addition, the aerosol composition is generally size-dependent, leading to different values of $K_{\mathrm{e}}$ for different aerosol sizes. Since these effects can only be taken into account in the size-dependent model, but not in the bulk approach, their implementation leads to a systematic inequality of Eq. (16). In this case the source/sink terms for $\mathrm{NH}_{3}$ and $\mathrm{HNO}_{3}$ are not calculated by relaxation of the bulk species, but from the sum of the individual source/sink terms for the $\mathrm{NH}_{4} \mathrm{NO}_{3}$ class bins $\left(Q_{c_{i}}\right)$.

2.5 Calculation of modelled deposition velocities and comparison with measured values

To ensure comparability between measurements, measured deposition velocities $\left(V_{\mathrm{d}}\right)$ are usually extrapolated to the surface. The apparent surface deposition velocity of the hydrophilic aerosol ( $\left.V_{\mathrm{ds}, \mathrm{hp}}\right)$ is calculated from $F_{c_{i h}}$ as:

$$
\begin{aligned}
V_{\mathrm{ds}, \mathrm{hp}}\left(R_{i h}\right) & =V_{\mathrm{d}, \mathrm{hp}}\left(z_{0}, R_{i h}\right) \\
& =\left(V_{\mathrm{d}, \mathrm{hp}}^{-1}\left(z_{h}, R_{i h}\right)-R_{\mathrm{a}}\left(z_{h}\right)\right)^{-1} \\
& =\left(-\frac{c_{i h}}{F_{c_{i h}}}-R_{\mathrm{a}}\left(z_{h}\right)\right)^{-1} .
\end{aligned}
$$

If $f_{\mathrm{hp}}\left(R_{\mathrm{p}}\right)$ is the size-dependent number fraction of the hydrophilic aerosol, the overall deposition velocity predicted by the model for the bulk aerosol is given by:

$$
\begin{aligned}
V_{\mathrm{ds}, \text { mod }}\left(R_{i h}\right) & =f_{\mathrm{hp}}\left(R_{i h}\right) V_{\mathrm{ds}, \mathrm{hp}}\left(R_{i h}\right) \\
& +\left[1-f_{\mathrm{hp}}\left(R_{i h}\right)\right] V_{\mathrm{ds}, \text { inert }}\left(R_{i h}\right),
\end{aligned}
$$

where $V_{\mathrm{ds} \text {, inert }}$ is the same parameterization of the deposition velocity of inert tracers used in Eqs. (12) and (13).

Although during field experiments, such as the Elspeet campaign, size-segregated deposition velocities are often inferred from particle number flux measurements, rather than 
mass fluxes, these particle numbers are measured at a constant size and the measured $V_{\mathrm{ds}}$ can therefore directly be compared with $V_{\mathrm{ds}, \text { mod }}$.

2.6 Definition of the missing boundary condition - the equilibrium height

As a further set of boundary conditions, the values of $R_{i h}^{\prime}$ need to be defined at a certain height. By reducing the problem of calculating $c(z)$ to the calculation of the vertical gradients in $n_{i h}$ and $R_{i h}$, it has been achieved that the $n_{i h}$ are affected only by the surface interaction, while gradients in $R_{i h}$ are only the result of chemical conversion processes. As a result, $R_{i h}^{\prime}$ at a certain height $\left(z_{\text {eq }}\right)$ is zero if (and only if) there is thermodynamic equilibrium at $z_{\text {eq }}$. Equilibrium can theoretically be found at more than one height or may not be obtained over the height range of the measurements at all. Two different opinions dominate the literature: Kramm and Dlugi (1994) introduced thermodynamic equilibrium at $z_{0}$ in order to be able to use parameterizations of the laminar boundary layer resistance $\left(R_{\mathrm{b}}\right)$ derived for inert tracers. This boundary condition is introduced out of mathematical necessity rather than for physical reasons. In fact, concentration gradients are particularly pronounced in the laminar sublayer, while different conditions at the surface may be the source of disequilibrium, which would suggest that here equilibrium is unlikely to be found. By contrast, Duyzer et al. (1995) argue for the $\mathrm{NO}-\mathrm{O}_{3}-\mathrm{NO}_{2}$ system that photochemical equilibrium is more likely to be found well above the surface, and their model consequently "forces" the flux-divergence to converge towards zero for increasing $z$. The same reasoning is likely to apply to the $\mathrm{NH}_{3}-\mathrm{HNO}_{3}$ $\mathrm{NH}_{4} \mathrm{NO}_{3}$ system (J. H. Duyzer, personal communication), although it may be that due to changing conditions of precursor gas concentrations, temperature and humidity periods occur when there is no equilibrium even remote from the surface.

In general, it is necessary to distinguish between different causes of disequilibrium: disequilibrium caused by advection will be largest well above the ground and relax towards the ground, while disequilibrium driven by the difference in surface exchange rates will be large at the surface $\left(z_{0}\right)$ and vanish at higher heights. In the following, the two cases, $z_{\text {eq }}=z_{0}$ and $z_{\text {eq }}=z_{\text {ref }} \gg z_{0}$, are investigated separately.

Equation (9) implies that at $z_{\text {eq }}$, where $R_{i h}^{\prime}=0$, the relative concentration gradient equals the relative number density gradient $\left(c^{\prime} / c=n^{\prime} / n\right)$. Hence, since $n^{\prime}$ was derived from a parameterization of $V_{\mathrm{ds} \text {,inert }}$ and $R_{\mathrm{a}}$, at $z_{\mathrm{eq}}$, the value of $c^{\prime}$ (and therefore the mass flux $F_{c_{i}}$ ) also obeys this relationship, i.e. $V_{\mathrm{ds}, \mathrm{hp}}\left(R_{i h_{\mathrm{eq}}}\right)=V_{\mathrm{ds} \text {, inert }}\left(R_{i h_{\mathrm{eq}}}\right)$ or:

$$
\begin{aligned}
F_{c_{i}}\left(z_{\mathrm{eq}}\right) & =-K_{\mathrm{H}}\left(z_{\mathrm{eq}}\right) \frac{z_{\mathrm{eq}}}{b} c_{i h_{\mathrm{eq}}}^{\prime} \\
& =-\frac{c_{i h_{\mathrm{eq}}}}{R_{\mathrm{a}}}\left(z_{\mathrm{eq}}\right)+V_{\mathrm{ds}, \text { inert }}^{-1}\left(R_{i h_{\mathrm{eq}}}\right) .
\end{aligned}
$$

This implies that if $z_{\mathrm{eq}}=z_{\text {ref }}$, the best agreement between the measured $V_{\mathrm{ds}}$ and $V_{\mathrm{ds} \text {,inert }}$ ought to be found at $z_{\text {ref }}$ rather
Table 1. Input parameters for theoretical model scenarios (Sect. 3). All concentrations are in $\mathrm{nmol} \mathrm{m}^{-3}$.

\begin{tabular}{lcccc}
\hline Parameter & Scenario A & Scenario B & Scenario C & Scenario D \\
\hline$z_{\text {eq }}$ & $z_{0}$ & $z_{\text {ref }}$ & $z_{0}$ & $z_{\text {ref }}$ \\
$K_{\mathrm{m}} / K_{\mathrm{e}}$ & $>1(\mathrm{gtpc})$ & $>1$ (gtpc) & $<1$ (evapor.) & $<1$ (evapor.) \\
$\chi \mathrm{NH}_{3}(0.5 \mathrm{~m})$ & 450 & 500 & 500 & 450 \\
$\chi \mathrm{NH}_{3}(10 \mathrm{~m})$ & 500 & 250 & 300 & 500 \\
$\chi \mathrm{HNO}_{3}(0.5 \mathrm{~m})$ & Dep. at $V_{\max }$ & dep. at $V_{\max }$ & 80 & dep. at $V_{\max }$ \\
$\chi \mathrm{HNO}_{3}(10 \mathrm{~m})$ & 100 & 100 & 100 & 100 \\
$\chi \mathrm{NH}_{4} \mathrm{NO}_{3}(10 \mathrm{~m})$ & 50 & 50 & 50 & 100 \\
$\begin{array}{l}\text { Are results } \\
\text { consistent with }\end{array}$ & & & & \\
observation of small & yes & no & no & yes \\
particle emission & & & & \\
by eddy-covariance? & & & & \\
\hline Additional input & & & & \\
\hline
\end{tabular}

Additional input parameters used commonly for all scenarios are $z_{0}=0.03 \mathrm{~m}, z_{\text {ref }}=10 \mathrm{~m}, u(1 \mathrm{~m})=4 \mathrm{~m} \mathrm{~s}^{-1}, u_{*}=0.3 \mathrm{~m} \mathrm{~s}^{-1}, L=\infty$, $H=\lambda E=0, \alpha=0.1$.

than at $z_{0}$. As discussed below, this result has important consequences for the apparent deposition velocities. In the following, four theoretical situations are investigated: 1) condensational particle growth and 2) aerosol evaporation, each combined with a) surface $\mathrm{NH}_{3}$ emission and equilibrium at a high height $\left(z_{\text {eq }}=z_{\text {ref }}\right)$ and b) $\mathrm{NH}_{3}$ deposition and $z_{\text {eq }}=z_{0}$.

\section{Theoretical model studies}

\subsection{Input parameters}

To examine the theoretical effect of gtpc and aerosol evaporation on the height-dependent vertical fluxes of differently sized particles, a simplified model scenario is used. The aerosol is assumed to consist of pure $\mathrm{NH}_{4} \mathrm{NO}_{3}\left(S_{i h}=1 ; y_{i}=0\right.$; $f_{\mathrm{hp}}=1$ ), the mass distribution (and therefore also the number distribution) of which is log-normally distributed at the reference height:

$c\left(\ln R_{\mathrm{p}}\right)=\frac{c_{\mathrm{tot}}}{\sqrt{2 \pi} \ln \sigma_{\mathrm{G}}} \exp \left(-\frac{\left(\ln R_{\mathrm{p}}-\ln R_{\mathrm{p}, \mathrm{G}}\right)^{2}}{2 \ln ^{2} \sigma_{\mathrm{G}}}\right)$,

where $c_{\text {tot }}$ is the total concentration of $\mathrm{NH}_{4} \mathrm{NO}_{3}, \sigma_{\mathrm{G}}$ and $R_{\mathrm{p}, \mathrm{G}}$ are the geometric standard deviation and mass median radius (e.g. Seinfeld and Pandis, 1997), which were set to typical values of 1.6 and $0.46 \mu \mathrm{m}$, respectively (Bai et al., 1995).

For the test runs $V_{\mathrm{ds} \text {, inert }}\left(R_{\mathrm{p}}\right)$ is parameterized according to measurements at Elspeet that appear to be unaffected by gpic (Nemitz et al., 2004b), vertical gradients of $T$ and $h$ are neglected (latent heat flux $(\lambda E)=$ sensible heat flux $(H)=0)$, together with the Kelvin effect, and test runs are restricted to neutral conditions $(L=\infty)$. Further input parameters are listed in Table 1. In the following section, $K_{\mathrm{m}}$ is the actual (measured or modelled) product of the precursor gases $\left(K_{\mathrm{m}}=\left[\mathrm{NH}_{3}\right] \times\left[\mathrm{HNO}_{3}\right]\right)$ at a given height. 
Scenario A:
$K_{\mathrm{m}}>K_{\mathrm{e}}(\mathrm{gtpc})$
$z_{\mathrm{eq}}=z_{0}$
$\mathrm{NH}_{3}$ deposition

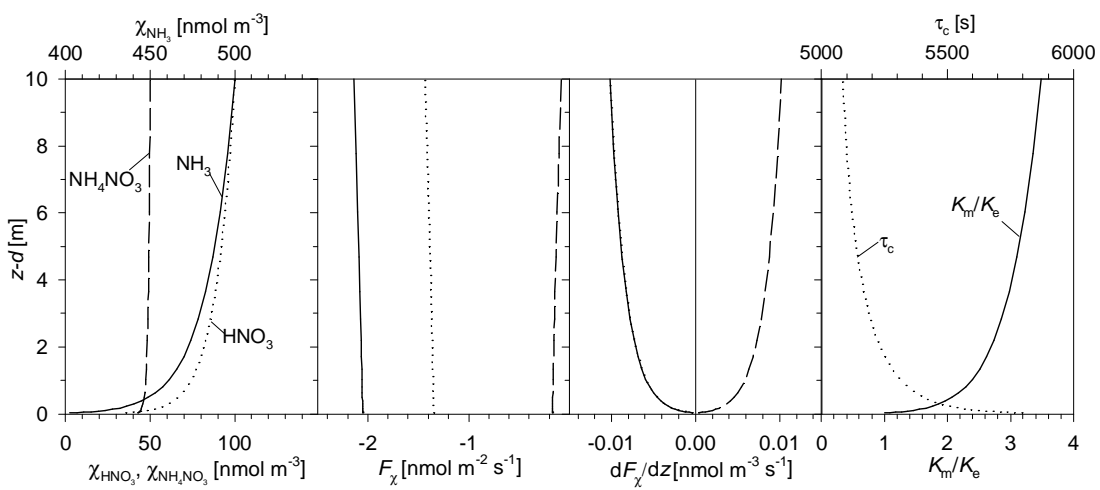

Scenario B:

$K_{\mathrm{m}}>K_{\mathrm{e}}(\mathrm{gtpc})$

$z_{\text {eq }}=z_{\text {ref }}$

$\mathrm{NH}_{3}$ emission

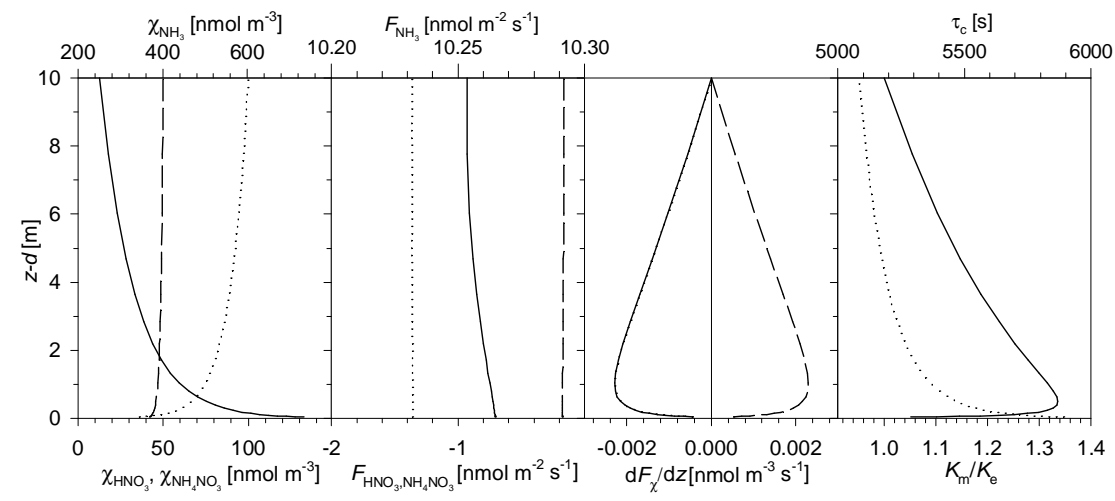

Scenario C:

$K_{\mathrm{m}}<K_{\mathrm{e}}$ (evap.)

$z_{\mathrm{eq}}=z_{0}$

$\mathrm{NH}_{3}$ emission

Scenario D:

$K_{\mathrm{m}}<K_{\mathrm{e}}$ (evap.)

$z_{\mathrm{eq}}=z_{\text {ref }}$

$\mathrm{NH}_{3}$ deposition
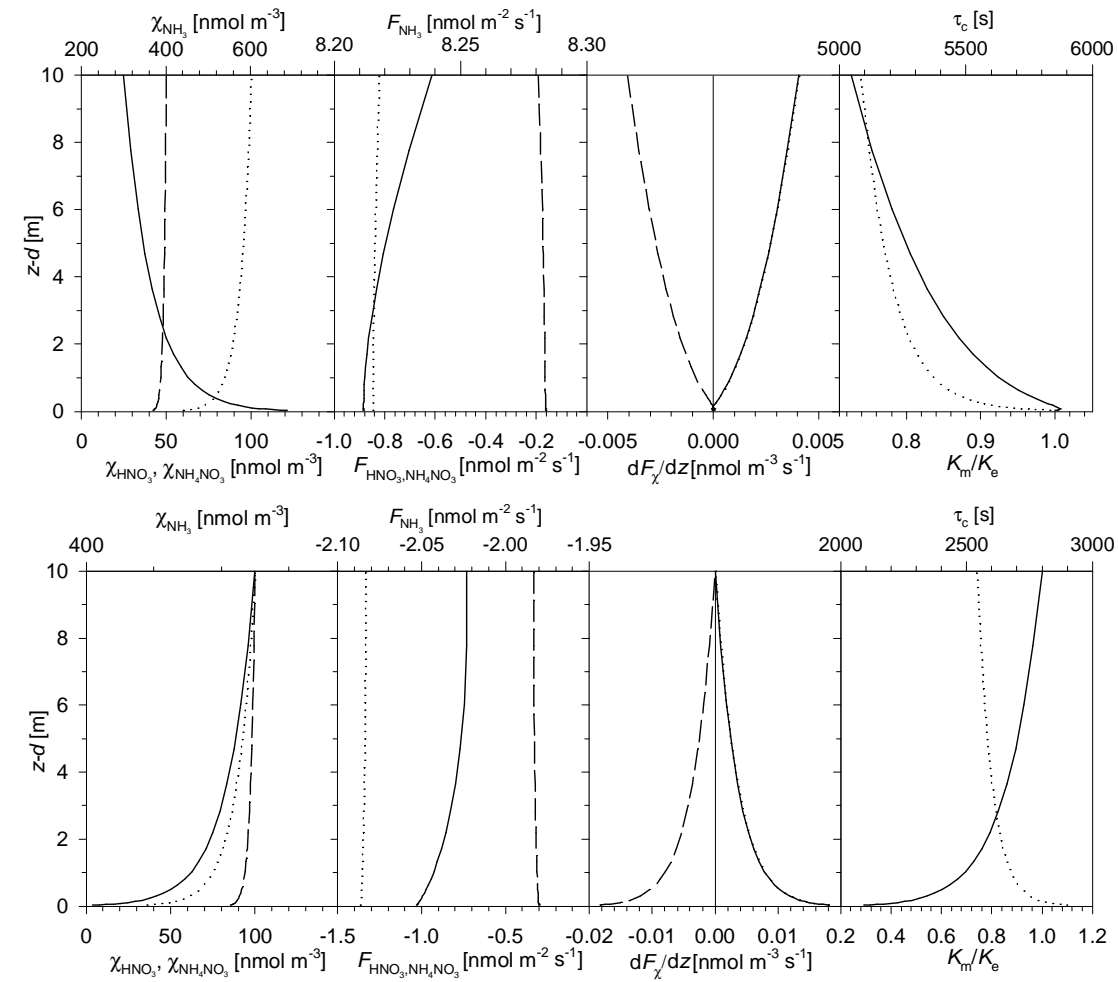

Fig. 3. Results of Scenarios A-D for bulk aerosol and gas species calculated with the size-segregated model, showing gradients of concentration $(\chi)$, flux $\left(F_{\chi}\right)$, flux divergence $\left(\mathrm{d} F_{\chi} / \mathrm{d} z\right)$, ratio of modelled and equilibrium concentration products $\left(K_{\mathrm{m}} / K_{\mathrm{e}}\right)$ and chemical time-scale $\left(\tau_{\mathrm{c}}\right)$. Note that the flux divergences of $\mathrm{HNO}_{3}$ and $\mathrm{NH}_{3}$ are identical and thus cannot be distinguished. 
3.2 Identification of conditions causing apparent emission of small particles through four theoretical scenarios

\subsubsection{Scenario A: $\mathrm{NH}_{3}$ deposition, $\mathrm{z}_{\mathrm{eq}}=\mathrm{z}_{0}, K_{\mathrm{m}}>K_{\mathrm{e}}$}

Former studies have concentrated on conditions during which the equilibrium value of the dissociation constant was exceeded well above the surface, for example in the vicinity of local sources of $\mathrm{NH}_{3}$ or $\mathrm{HNO}_{3}$ (e.g. Kramm and Dlugi, 1994). In this situation $\mathrm{NH}_{3}$ may either be deposited or emitted; however, equilibrium at the surface is more likely to be obtained when $\mathrm{NH}_{3}$ is deposited. Figure 3a shows the results for the bulk gas and aerosol species as calculated with the size-dependent model, including profiles of concentrations, fluxes and flux divergences as well as the ratio $K_{\mathrm{m}} / K_{\mathrm{e}}$ and $\tau_{\mathrm{c}}$. The large chemical time-scale of $>1 \mathrm{~h}$ is the result of low total particle loadings (note that $\mathrm{NH}_{4} \mathrm{NO}_{3}$ is the only aerosol considered) and the value of $\alpha$ selected. As a result, the bulk fluxes are almost constant with height: the deposition fluxes of $\mathrm{NH}_{3}$ and $\mathrm{HNO}_{3}$ increase slightly with height, while the deposition of $\mathrm{NH}_{4} \mathrm{NO}_{3}$ decreases. The agreement in the flux divergence of bulk $\mathrm{NH}_{4} \mathrm{NO}_{3}$ and the gaseous species may be taken as a validation that the size-resolved modelling approach is consistent with the model for the bulk species and the principle of mass conservation.

Figure $4 \mathrm{a}$ shows the resulting size-dependence of the surface deposition velocity derived from the concentrations and fluxes at various heights according to Eq. (18). Despite the large chemical time-scales the effect on the apparent $V_{\mathrm{ds}}$ of small particles is significant: with increasing height, for small particles $V_{\mathrm{ds}}$ changes from positive values (deposition) to increasingly larger negative values (apparent emission).

Depending on the height, the sign change in the flux occurs in the region $R_{\mathrm{p}}=0.1-0.3 \mu \mathrm{m}$. Because these small particles carry little mass, the bulk $\mathrm{NH}_{4} \mathrm{NO}_{3}$ flux shows deposition at all heights, despite the upward flux of small particles.

\subsubsection{Scenario B: $\mathrm{NH}_{3}$ emission, $\mathrm{z}_{\mathrm{eq}}=\mathrm{Z}_{\mathrm{ref}}, K_{\mathrm{m}}>K_{\mathrm{e}}$}

In this scenario $K_{\mathrm{e}}$ is exceeded due to $\mathrm{NH}_{3}$ emission and equilibrium is maintained at the upper boundary height. As with the previous example, $K_{\mathrm{m}}>K_{\mathrm{e}}$ leads to aerosol production and a reduction of the $\mathrm{NH}_{4} \mathrm{NO}_{3}$ deposition flux with height (Fig. 3b), which is also reflected in a decrease of $V_{\mathrm{ds}}$ with height (Fig. 4b). $\quad K_{\mathrm{m}}$ is affected by two contrasting concentration gradients and therefore shows a maximum at a height of about $0.5 \mathrm{~m}$, while at the surface the concentrations again approach equilibrium. This is directly reflected in the flux divergence, which is proportional to the departure from equilibrium (Eq. 1).

The resulting $V_{\mathrm{ds}}$ (Fig. 4b) shows interesting features: $V_{\mathrm{ds}}$ derived for $z_{\text {ref }}$ matches $V_{\mathrm{ds} \text {,inert }}$ used to calculate $n^{\prime}\left(z_{0}\right)$, while $V_{\mathrm{ds}}$ derived from lower heights exceeds this value. The sign of the $\mathrm{NH}_{4} \mathrm{NO}_{3}$ flux-divergence is positive and therefore in agreement with the bulk modelling presented
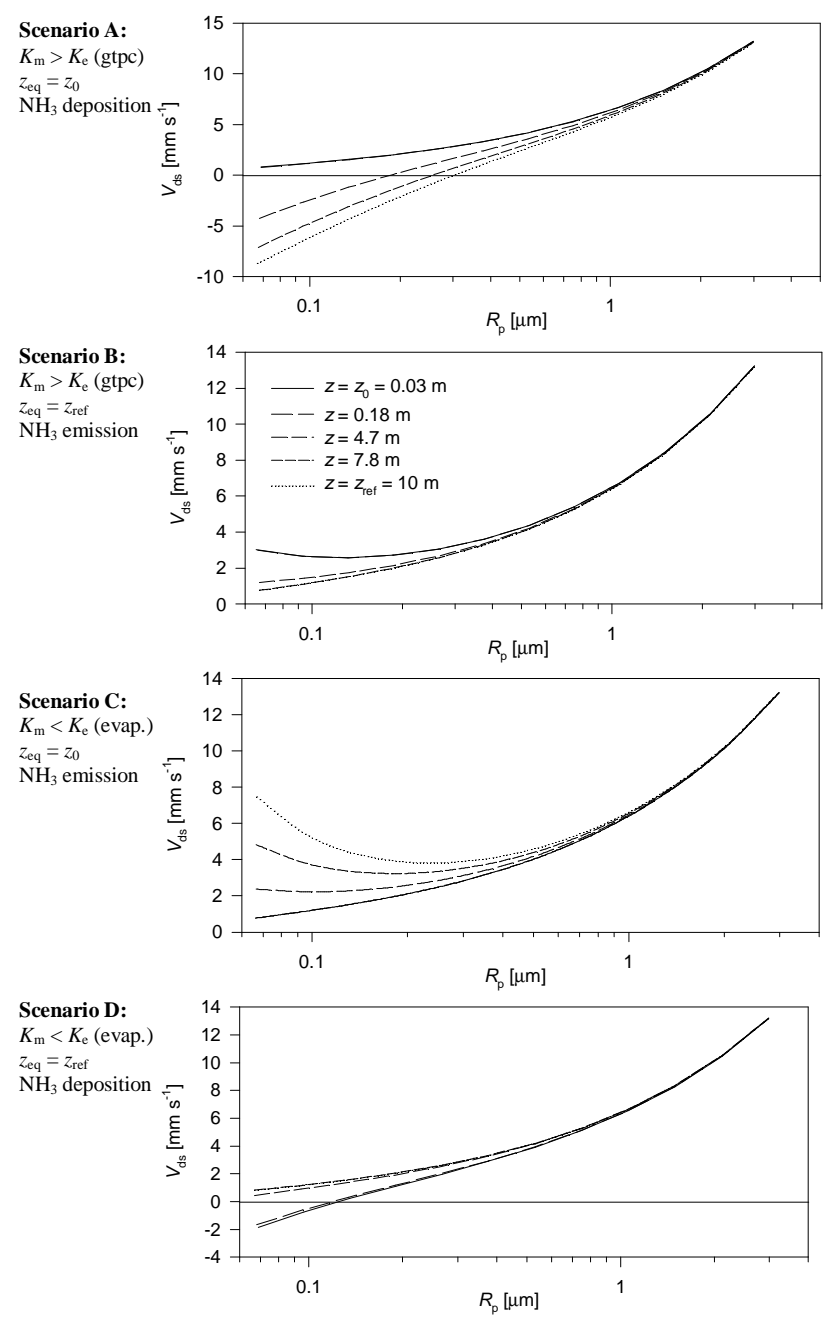

Fig. 4. Modelled surface deposition velocities $\left(V_{\mathrm{ds}}\right)$ as a function of particle radius $\left(R_{\mathrm{p}}\right)$ for Scenarios $\mathrm{A}$ to $\mathrm{D}$ as they would be inferred from size segregated eddy-correlation flux measurements at various heights $(z)$.

before. While gtpc may intuitively be expected to lead to reduced aerosol deposition or apparent emission fluxes at higher heights, the plot of $V_{\mathrm{ds}}$ indicates faster deposition than $V_{\mathrm{ds} \text {,inert }}$ at lower heights, if derived by EC. While the particles (numbers) are exchanged at $V_{\mathrm{ds} \text {,inert }}$ at the surface, the particle growth during the deposition process causes the (mass) deposition flux to increase towards the ground. At the time the particles interact with the surface the flux is still given by the concentration just above the ground and $V_{\mathrm{ds} \text {,inert }}$. This scenario shows that if equilibrium is attained at a higher height and exceeded near the surface, gtpc will result in a decrease of the particle deposition flux with height (with the potential for apparent particle emission fluxes if determined by gradient methods), but apparent emission from the sizesegregated EC measurements will never occur, as the flux follows the parameterization of the surface deposition at the equilibrium height, which serves as a lower limit. 

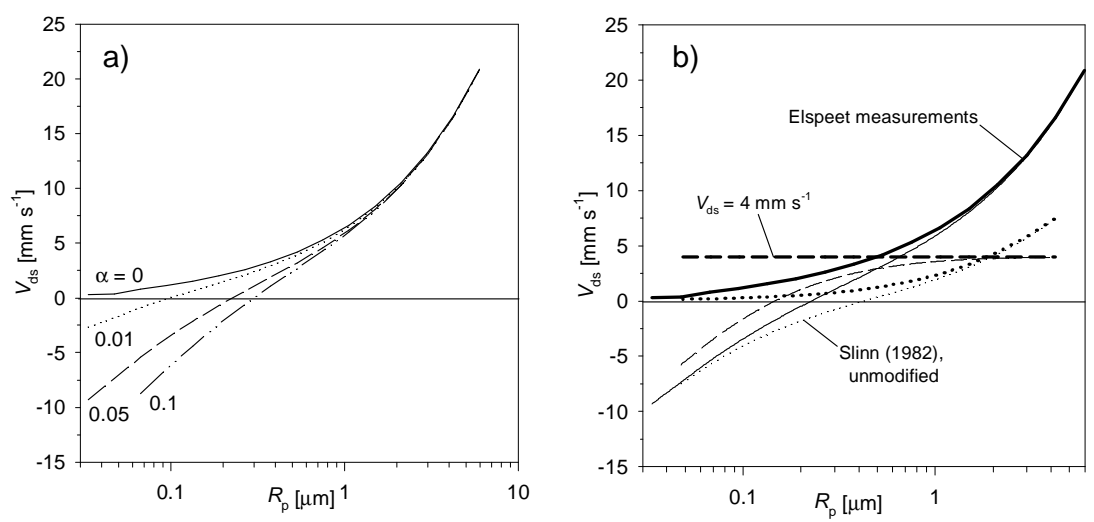

Fig. 5. (a) Dependency of the modelled $V_{\mathrm{ds}}$ derived at $z=10 \mathrm{~m}$ for Scenario A on the value of the sticking coefficient $(\alpha)$. (b) The prediction of $V_{\mathrm{ds}}$ derived for $z=2 \mathrm{~m}$ (thin lines) resulting from three different parameterizations of $V_{\mathrm{ds}}$,inert (bold lines), according to Slinn (1982), (Nemitz et al., 2004b, Eq. 12) and $V_{\mathrm{ds} \text {, inert }} \equiv 4 \mathrm{~mm} \mathrm{~s}^{-1}$.

\subsubsection{Scenario C: $\mathrm{NH}_{3}$ emission, $\mathrm{z}_{\mathrm{eq}}=\mathrm{z}_{0}, K_{\mathrm{m}}<K_{\mathrm{e}}$}

In this scenario $K_{\mathrm{m}}<K_{\mathrm{e}}$ leads to aerosol evaporation at all heights except the surface. This requirement can only be fulfilled, if $\mathrm{NH}_{3}$ shows a strong emission gradient (leading to a decrease of $K_{\mathrm{m}}$ with height) or if $K_{\mathrm{e}}$ increases with increasing height, either due to a positive latent heat flux or a negative sensible heat flux. Since the theoretical model runs presented here do not consider gradients in $K_{\mathrm{e}}, \mathrm{NH}_{3}$ is assumed to be emitted, bearing in mind that this may be in contradiction to the assumption of surface equilibrium. Consistent with aerosol evaporation, the $\mathrm{NH}_{4} \mathrm{NO}_{3}$ deposition flux increases with height (Fig. 3c) and $V_{\mathrm{ds}}$ derived from higher heights shows increasingly more positive divergence from the input parameterization.

\subsubsection{Scenario D: $\mathrm{NH}_{3}$ deposition, $\mathrm{z}_{\mathrm{eq}}=\mathrm{Z}_{\mathrm{ref}}, K_{\mathrm{m}}<K_{\mathrm{e}}$}

The last scenario considers an atmosphere in which concentrations are in equilibrium well above the ground, but the deposition of $\mathrm{NH}_{3}$ and $\mathrm{HNO}_{3}$ reduces $K_{\mathrm{m}}$ towards the surface. As a result $\mathrm{NH}_{4} \mathrm{NO}_{3}$ evaporates and therefore shows a negative flux divergence (Fig. 3d) similar to the previous example. In this case, $V_{\mathrm{ds}}$ follows $V_{\mathrm{ds} \text {, inert }}$ at the reference height (Fig. 4d), while at lower heights $V_{\mathrm{ds}}$ for small particles is modified towards emission. Hence, although $\mathrm{NH}_{4} \mathrm{NO}_{3}$ deposition increases with increasing height, apparent emission may be found at lower heights. This observation does not represent real emission at the surface, but is rather an artefact caused by the size change of the particles (Eqs. 9 and 11). Once the particles hit the surface, evaporation ceases to cause flux divergence and the surface deposition flux follows $V_{\mathrm{ds}, \text { inert }}$.

To summarize the model predictions, simultaneous apparent emission of small particles and deposition of large particles, as observed in the field, can be found either if $K_{\mathrm{m}}>K_{\mathrm{e}}$ (gtpc) and equilibrium is obtained at the surface (Scenario A), or if $K_{\mathrm{m}}<K_{\mathrm{e}}$ (aerosol evaporation) and equilibrium is obtained at $z_{\text {ref }} \gg z_{0}$ (Scenario D). While in the first case apparent emission becomes more pronounced at higher heights, in the second case apparent emission is most distinct close to the ground.

\subsection{Factors influencing the radius at which the flux changes sign}

According to the chemical time-scale of Eq. (4) the gpic mass flux to or from the aerosol $\left(\mathrm{d} c / \mathrm{d} t=\mathrm{d} F_{\mathrm{c}} / \mathrm{d} z ;\right.$ Eq. 1) is proportional to $R_{\mathrm{p}}$ in the continuum and $\propto R_{\mathrm{p}}^{2}$ in the non-continuum regime (cf. Dahlin et al., 1981), while the temporal change in the radius $\left(\mathrm{d} R_{\mathrm{p}} / \mathrm{d} t\right)$ is proportional to $(\mathrm{d} c / \mathrm{d} t)^{1 / 3}$. As a result $\mathrm{d} R_{\mathrm{p}} / \mathrm{d} t$ is $\propto R_{\mathrm{p}}^{-1}$ in the continuum regime and converges towards a constant value for small particles (non-continuum regime). Thus, growth and evaporation have a more pronounced effect on the radius of smaller particles. In addition to the particle radius, $\tau_{\mathrm{c}}$ is also generally influenced by the sticking coefficient $(\alpha)$, which for the condensation of $\mathrm{NH}_{3}$ and $\mathrm{HNO}_{3}$ onto existing particles is controversial (e.g. Dassios and Pandis, 1999; Rudolf et al., 2001). Figure 5a shows the model results for various values of $\alpha$.

According to the theoretical prediction by Slinn (1982), but also the parameterization obtained at Elspeet (Nemitz et al., 2004b), small particles deposit slowly, and condensation or evaporation has more time to modify their size. This also explains why the gpic effect is largest for small particles. To demonstrate the effect of the parameterization of $V_{\mathrm{ds}}$,inert on the model result, the model was run with the same input parameters as before but varying the parameterization of $V_{\mathrm{ds} \text {,inert }}$ (Fig. $5 \mathrm{~b}$ ). The parameterization by Slinn (1982) was compared with the parameterization derived for Elspeet, evaluated for the same conditions $\left(u_{*}=0.3 \mathrm{~m} \mathrm{~s}^{-1} ; L=-50 \mathrm{~m}\right)$ as well as to a size-independent value of $V_{\mathrm{ds} \text {,inert }}\left(R_{\mathrm{p}}\right) \equiv 4 \mathrm{~mm} \mathrm{~s}^{-1}$. The comparison shows that the smaller the value of $V_{\mathrm{ds} \text {, inert }}$, the more likely becomes the observation of particle emission. 


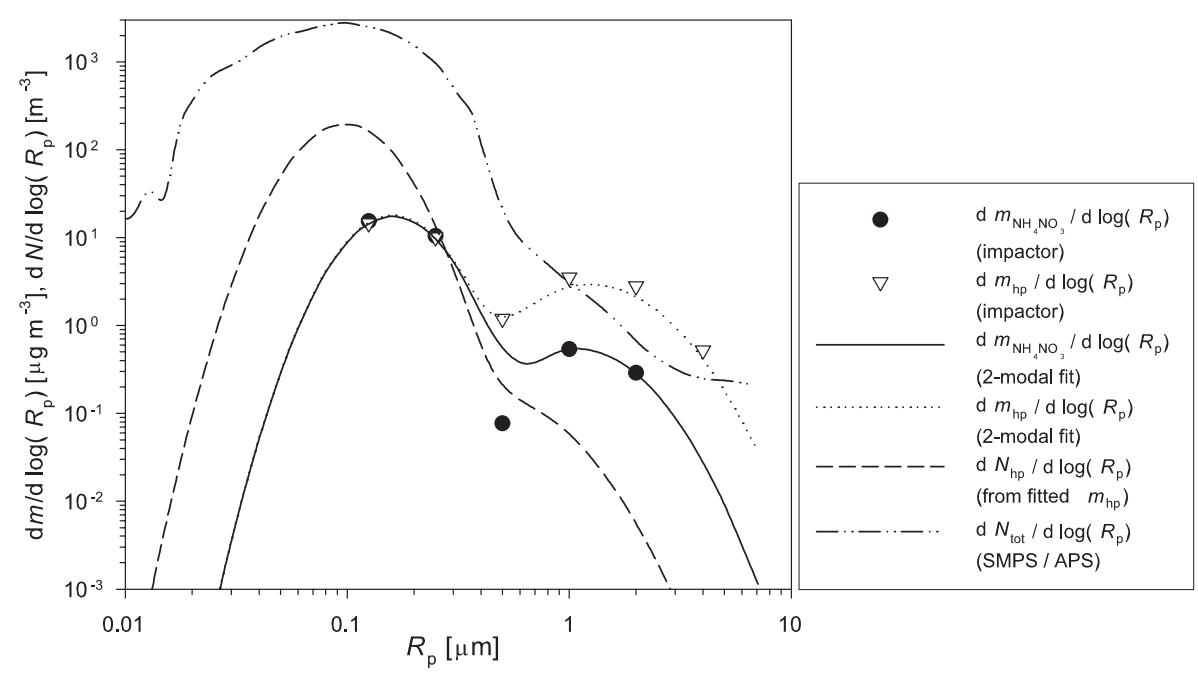

Fig. 6. Input mass distribution of $\mathrm{NH}_{4} \mathrm{NO}_{3}$ aerosol $\left(\mathrm{d} m_{\mathrm{NH}_{4} \mathrm{NO}_{3}} / \mathrm{d} \log \left(R_{\mathrm{p}}\right)\right)$ and total hydrophilic $\left(\mathrm{d} m_{\mathrm{hp}} / \mathrm{d} \log \left(R_{\mathrm{p}}\right)\right)$ aerosol as estimated from the cascade impactor data, normalized by the $\mathrm{SJAC}_{\mathrm{NH}}^{+}$concentration for 5 June 1996 13:00 GMT. Also shown is the resulting number distribution $\left(\mathrm{d} N_{\mathrm{hp}} / \mathrm{d} \log \left(R_{\mathrm{p}}\right)\right)$, together with the size distribution of the total aerosol $\left(\mathrm{d} N_{\mathrm{tot}} / \mathrm{d} \log \left(R_{\mathrm{p}}\right)\right)$ as measured with the combination of SMPS and APS.

As mentioned above, surface tension elevates gas partial pressures above strongly curved surfaces, such as small particles, compared with flat surfaces. For Scenario A the Kelvin effect counteracts the tendency for smaller particles to grow faster, while it leads to enhanced evaporation of small particles in Scenario D: for $R_{\mathrm{p}}<0.2 \mu \mathrm{m}$ the predicted $V_{\mathrm{ds}}(2 \mathrm{~m})$ becomes increasingly reduced by the Kelvin effect. The influence of the Kelvin effect becomes larger for gas concentrations close to thermodynamic equilibrium. Finally, the observations of bi-directional particle fluxes by EC depends on the shape of the particle number size distribution. For example, if particle growth modifies a size bin where the size distribution increases $\left(\mathrm{d} N / \mathrm{d} R_{\mathrm{p}}>0\right)$, more particles are expected to grow out of a size bin than into the size bin. Conversely, if such an aerosol is affected by particle evaporation, more particles are expected to "shrink" into the size bin than out of the size bin. The opposite holds true if $\mathrm{d} N / \mathrm{d} R_{\mathrm{p}}<0$.

\section{Size-dependent modelling of gtpc effects at Elspeet}

In this section the size-dependent gpic model is applied to simulate measurement data obtained during the Elspeet campaign (Nemitz et al., 2004a, 2004b). This study focuses on 5 June 1996, since on this day a nearly complete dataset was obtained under adequate fetch conditions, and apparent emission of small particles was observed during the second half of the day. From the preceding section it is found that emission of small particles may be the effect of either condensational particle growth (Scenario A) or particle evaporation (Scenario D). In the following both mechanisms of the $\mathrm{NH}_{3}$ $\mathrm{HNO}_{3}-\mathrm{NH}_{4} \mathrm{NO}_{3}$ system are applied to the Elspeet dataset and their plausibility discussed.

\subsection{The size distribution at the upper boundary height}

The model requires the input of the particle size-distributions at the reference height specifying: a) the mass of $\mathrm{NH}_{4} \mathrm{NO}_{3}$, b) the mass of all hydrophilic aerosol providing a reaction surface for the condensation/evaporation, from which the mass fraction $S_{\text {ref }, i}$ can be calculated, and c) the number distribution of the total aerosol, which is needed to derive $f_{\mathrm{hp}}\left(R_{\mathrm{p}}\right)$ and eventually $V_{\mathrm{ds}, \bmod }\left(R_{\mathrm{p}}\right)$ according to Eq. (10). For Elspeet the following information on the aerosol characterization was available (Nemitz et al., 2004b): low pressure impactor measurements of the size distribution of the major ionic aerosol components for several 12 -h periods, continuous (30 min) concentrations of particulate $\mathrm{NH}_{4}^{+}, \mathrm{NO}_{3}^{-}, \mathrm{Cl}^{-}$ and $\mathrm{SO}_{4}^{2-}$ (measured by a steam jet aerosol collector, SJAC, with online anion chromatography), as well as 1 -h values of the particle number distributions over the diameter range from $10 \mathrm{~nm}$ to $15 \mu \mathrm{m}$.

As discussed by Nemitz (1998), the size distributions of $\mathrm{NH}_{4}^{+}$and $\mathrm{NO}_{3}^{-}$measured at the site strongly depended on the air mass history (continental/maritime) as well as time of day. Given the higher size-resolution of the model compared with the impactor, the impactor data was inverted to obtain a bi-modal lognormal distribution (Dzubay and Hasan, 1990). Since $\mathrm{Cl}^{-}$and $\mathrm{SO}_{4}^{2-}$ are ignored in the present version of the model, all $\mathrm{NH}_{4}^{+}$was assumed to represent $\mathrm{NH}_{4} \mathrm{NO}_{3}$. The $\mathrm{NH}_{4} \mathrm{NO}_{3}$ size spectrum was further normalized by the total $\mathrm{NH}_{4}^{+}$concentration, measured by the SJAC at a higher temporal resolution. The size distribution of the hydrophilic aerosol mass was approximated by the sum of all analyzed ionic species and converted into a number distribution. This was used together with the total number size distribution measured with a combination of a Scanning Mobility Particle 


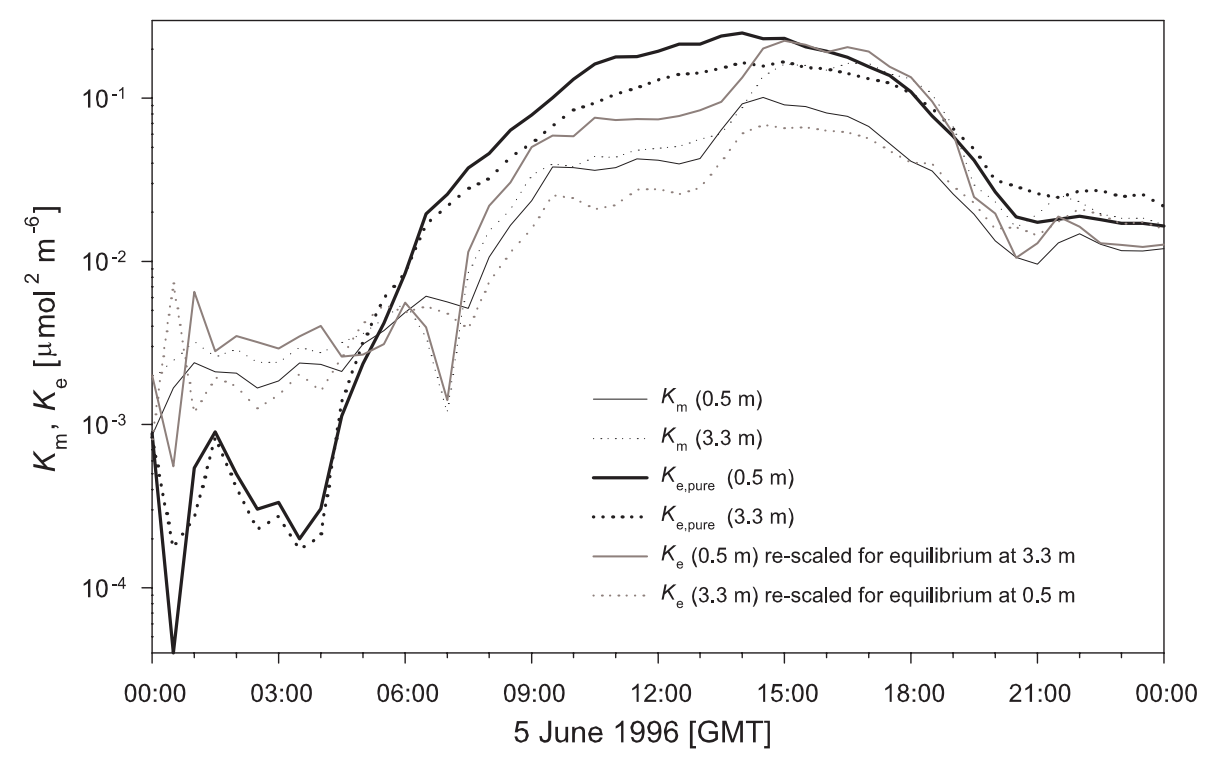

Fig. 7. $\mathrm{NH}_{4} \mathrm{NO}_{3}$ dissociation constants at Elspeet on 5 June 1996. The measured dissociation constant $\left(K_{\mathrm{m}}\right)$ and the theoretical equilibrium $\left(K_{\mathrm{e}}\right.$,pure $)$ values are shown for 0.5 and $3.3 \mathrm{~m}$, together with the theoretical values, re-scaled for equilibrium at the respective opposite height (see text).

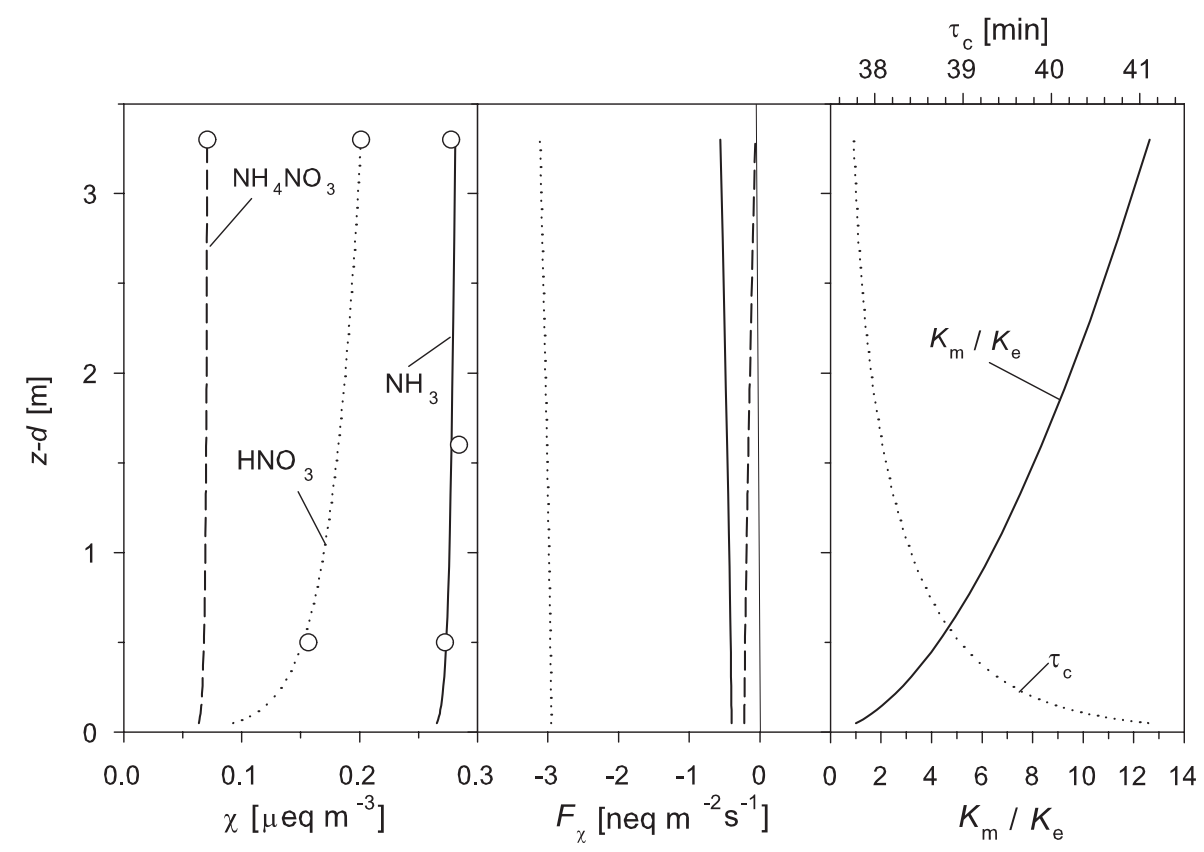

Fig. 8. Model output for 5 June 1996, 13:00 GMT using Scenario A. (a) Concentration gradients of the bulk species fitted to measured concentrations $(\bigcirc)$, (b) flux profiles and (c) height-dependence of the chemical time-scale $\left(\tau_{\mathrm{c}}\right)$ and the saturation ratio $\left(K_{\mathrm{m}} / K_{\mathrm{e}}\right)$. The run uses $\alpha=0.05$.

Sizer (SMPS) and an Aerodynamic Particle Sizer (APS 3310, both TSI Instruments) to calculate $f_{\mathrm{hp}}$, with the additional condition that $f_{\mathrm{hp}}\left(R_{\mathrm{p}}\right)=f_{\mathrm{hp}}(0.05 \mu \mathrm{m})$ for $R_{\mathrm{p}}<0.05 \mu \mathrm{m}$, because in this range the size distribution derived from the cascade impactor was considered unreliable. Example distributions are presented in Fig. 6.

\subsection{Concentration products at Elspeet}

Measured $\left(K_{\mathrm{m}}\right)$ and theoretical equilibrium concentration products of $\mathrm{NH}_{3} \times \mathrm{HNO}_{3}$ assuming pure $\mathrm{NH}_{4} \mathrm{NO}_{3}$ aerosol $\left(K_{\mathrm{e}, \text { pure }}\right)$ are presented for two heights in Fig. 7 (see also Nemitz, 1998). Equations (1) and (3) for the three chemical 

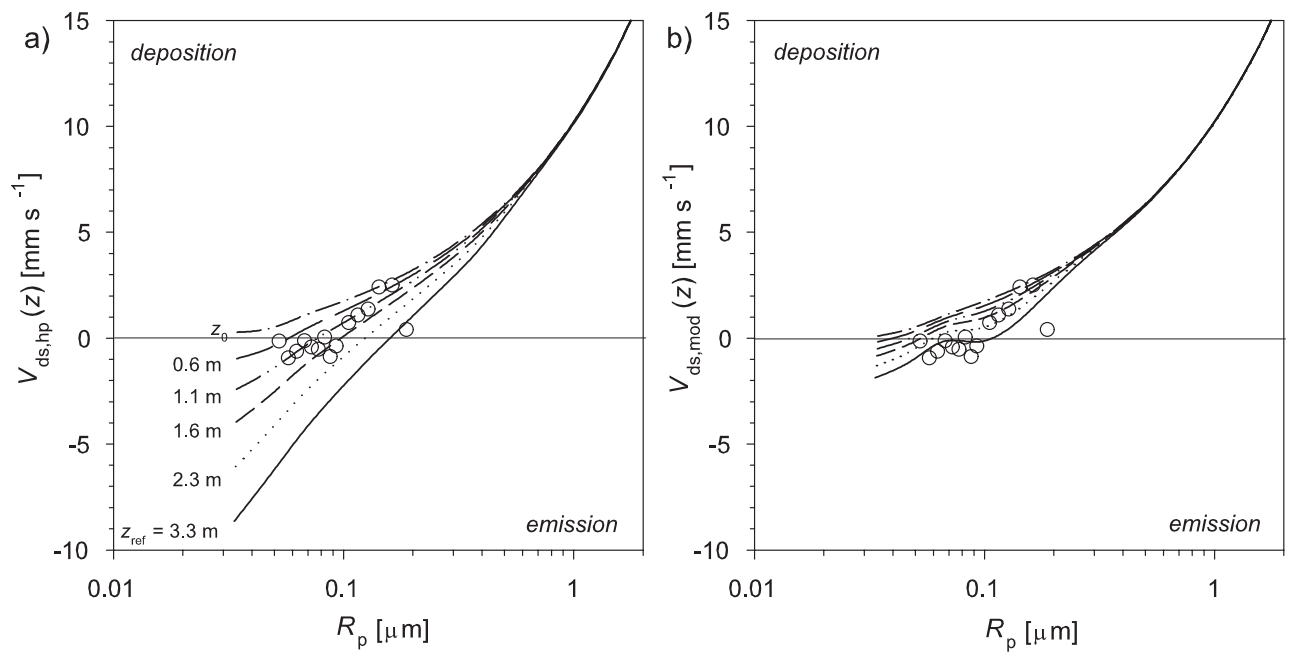

Fig. 9. Model output for 5 June, 13:00 GMT using Scenario A: apparent particle deposition velocity for (a) hydrophilic aerosol and (b) total aerosol as a function of particle radius $\left(R_{\mathrm{p}}\right)$ and height $(z)$. The parameterization of $V_{\mathrm{ds} \text {,inert }}$ is according to Eq. 12 of Nemitz et al. (2004b); $\alpha=0.05$. Circles $(\bigcirc)$ represent $V_{\mathrm{ds}}$ derived from eddy-correlation flux measurements at $z=2.65 \mathrm{~m}$ (Nemitz et al., 2004b).

species $\left(j=\mathrm{NH}_{3}, \mathrm{HNO}_{3}, \mathrm{NH}_{4} \mathrm{NO}_{3}\right)$ form a system of 6 coupled first order differential equations that may be solved numerically. The change of $K_{\mathrm{m}}$ with height is a result of the vertical gradients of the concentrations, while $K_{\mathrm{e} \text {,pure }}$ is determined by gradients in $T$ and $h$.

Although on 5 June $1996 \mathrm{NH}_{3}$ showed emission from 08:30-11:30 GMT, the deposition profile of $\mathrm{HNO}_{3}$ led to $K_{\mathrm{m}}(3.3 \mathrm{~m})>K_{\mathrm{m}}(0.5 \mathrm{~m})$ for most of the day. Due to gradients in $T$ and $h$, thermodynamic theory predicts a positive gradient in $K_{\mathrm{e}}$ only after 18:30 GMT, while for the rest of the day $K_{\text {e,pure }}(3.3 \mathrm{~m})<K_{\text {e,pure }}(0.5 \mathrm{~m})$. At Elspeet, $K_{\mathrm{m}}$ was (partly significantly) smaller than $K_{\mathrm{e}}$ for most of the time, and this would suggest potential for aerosol evaporation (Nemitz, 1998). For aqueous aerosol the thermodynamic prediction of $K_{\mathrm{e}}$ is uncertain, and several studies indicate that mixed $\mathrm{NH}_{4} \mathrm{NO}_{3}$ salts remain deliquescent even at $h$ well below the theoretical humidity of deliquescence (e.g. Dougle et al., 1998). Therefore the relative difference of $K_{\mathrm{m}}$ and $K_{\mathrm{e}}$ at both heights is assessed by the calculation of values re-scaled for equilibrium at the respective opposite height, i.e.:

$K_{\text {e,re-scale }}(0.5 \mathrm{~m})=\frac{K_{\mathrm{m}}(3.3 \mathrm{~m}) \times K_{\mathrm{e}, \text { pure }}(0.5 \mathrm{~m})}{K_{\mathrm{e}, \text { pure }}(3.3 \mathrm{~m})}$.

A similar value is calculated for $z=3.3 \mathrm{~m}$ (Fig. 7). If equilibrium is attained at a low height (e.g. $z=0.5 \mathrm{~m})$, i.e. $K_{\mathrm{e}}(0.5 \mathrm{~m})=K_{\mathrm{m}}(0.5 \mathrm{~m})$, it follows that $K_{\mathrm{m}}(3.3 \mathrm{~m})>K_{\mathrm{e}, \text { re-scale }}(3.3 \mathrm{~m})$, suggesting potential for aerosol evaporation (gtpc) above $0.5 \mathrm{~m}$. Similarly, if equilibrium is assumed at a higher height, i.e. $K_{\mathrm{e}}(3.3 \mathrm{~m})=$ $K_{\mathrm{m}}(3.3 \mathrm{~m})$, the resulting condition $K_{\mathrm{m}}(0.5 \mathrm{~m})<K_{\mathrm{e} \text {,re-scale }}$ $(0.5 \mathrm{~m})$ is consistent with aerosol evaporation potential below $3.3 \mathrm{~m}$. These two cases are therefore examples of the former Scenarios A and D, respectively, which were both found to be consistent with the observation of apparent emission of small particles. In Fig. 7 concentration products are presented for the measurement heights $(0.5$ and $3.3 \mathrm{~m})$, but for modelling purposes equilibrium is assumed either at $z_{0}$ or at $z_{\text {ref }}$, following Scenario A and D, respectively.

\subsection{Apparent aerosol emission by gas-to-particle formation (following Scenario A)}

Intuitively, apparent negative $V_{\mathrm{ds}}$, implying aerosol emission, would be attributed to aerosol formation or growth, which occurs for $K_{\mathrm{m}}>K_{\mathrm{e}}$. As outlined in the previous section, on 5 June 1996 at Elspeet this condition is fulfilled above the equilibrium height $\left(z_{\text {eq }}\right)$. Here $K_{\mathrm{e} \text {,pure }}(z)$ is therefore re-scaled according to Eq. (22) after each iteration (Sect. 2.3) such that $K_{\text {e,pure }}\left(z_{0}\right)=K_{\mathrm{m}}\left(z_{0}\right)$, where $K_{\mathrm{m}}\left(z_{0}\right)$ is the modelled concentration product at $z_{0}$. The output of an example run is shown in Fig. 8. While the relative change of the gas fluxes with height is small, the $\mathrm{NH}_{4} \mathrm{NO}_{3}$ flux shows deposition at the surface and emission at the reference height. Due to a strong deposition gradient of $\mathrm{HNO}_{3}$, the ratio of $K_{\mathrm{m}} / K_{\mathrm{e}}$ increases away from the surface raising the potential for condensation.

The values of $V_{\mathrm{ds}}\left(R_{\mathrm{p}}, z\right)$ resulting from the same run are shown in Fig. 9a for the hydrophilic aerosol and in Fig. 9b for the total aerosol, where they are compared with the $V_{\mathrm{ds}}$ measured by EC with the ASASP-x optical particle counter (Nemitz et al., 2004b). For the chosen value of $\alpha=0.05$ good agreement is found between predicted and measured values. In particular, the particle size at which the flux changes sign $\left(R_{\mathrm{p}}=0.1 \mu \mathrm{m}\right)$ is predicted correctly by the model.

To assess the ability of the model to reproduce temporal features of the measured bi-directional particle fluxes, the model was applied to the whole diurnal cycle of 5 June. The time-courses of the modelled and measured $V_{\mathrm{ds}}$ (Fig. 10) show some common features such as the switch 


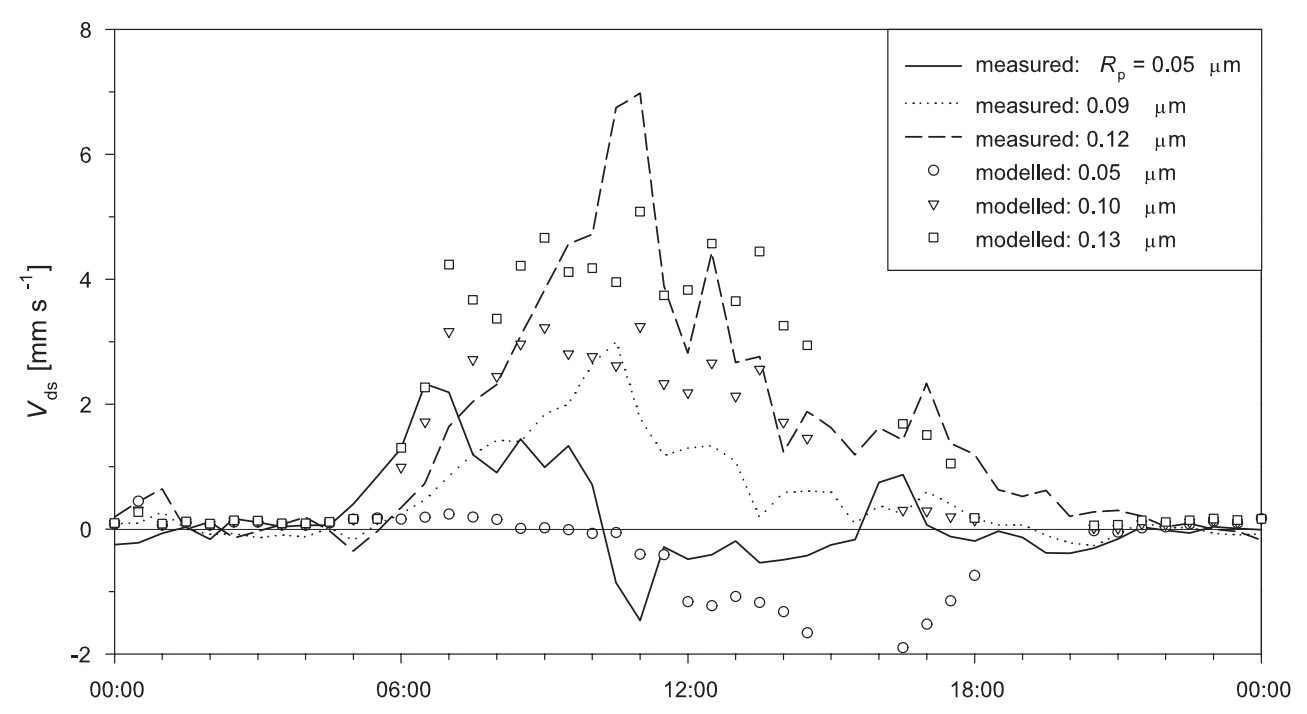

Fig. 10. Diurnal course of $V_{\mathrm{ds}}$ from 5 June 1996 model results using Scenario A, in comparison with measurements for three different size classes. Modelled values are for $\alpha=0.05$.

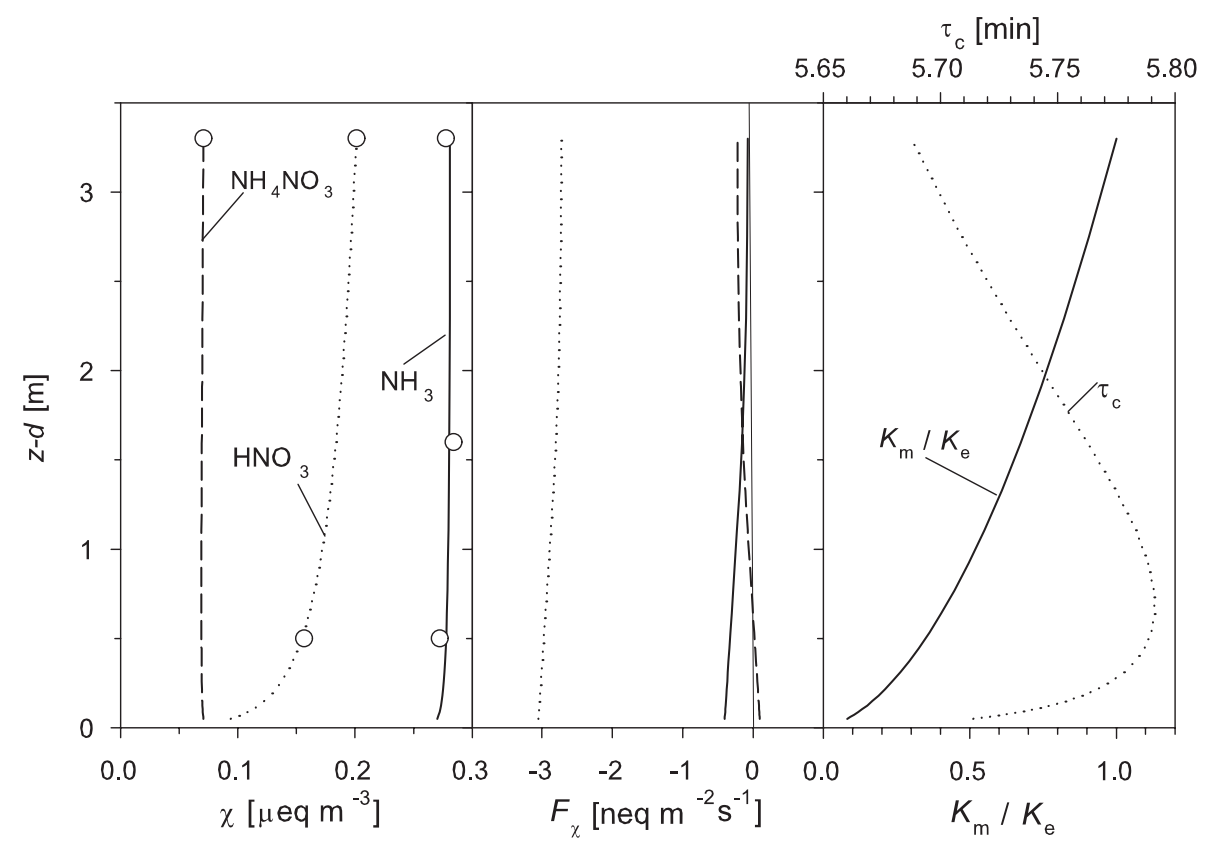

Fig. 11. Model output for 5 June 1996, 13:00 GMT using Scenario D. (a) Concentration gradients of the bulk species fitted to measured concentrations $(\bigcirc)$, (b) flux profiles and (c) height-dependence of the chemical time-scale $\left(\tau_{\mathrm{c}}\right)$ and the saturation ratio $\left(K_{\mathrm{m}} / K_{\mathrm{e}}\right)$. The run uses $\alpha=1$.

from deposition to emission for the $0.05 \mu \mathrm{m}$ particles at 10:00 GMT. However, the model tends to underestimate the effect of gtpc on the flux measurements of the $0.10 \mu \mathrm{m}$ particles and overestimates the effect on the $0.05 \mu \mathrm{m}$ size-range. For individual 30-min runs, the model predicts negative radii for certain $R_{i h}$ (no particles in size class $i$ at height $h$ ), leading to gaps in the modelled time-series. This problem became more pronounced for larger values of $\alpha$.
Interestingly, the model predicts enhanced $V_{\mathrm{ds}}$ around 07:00 GMT, when there was evaporation potential due to $K_{\mathrm{m}}>K_{\mathrm{e}, \text { rescale }}$ (Fig. 7), which is in agreement with Scenario $\mathrm{C}$ and was also picked up by the ASASP-x for the smallest size class. The relative difference of the surface exchange fluxes of $\mathrm{HNO}_{3}$ and $\mathrm{NH}_{3}$ between $z=3.3 \mathrm{~m}$ and $z_{0}$ is on average 5.2 and $10 \%$, respectively, with larger deposition found at $3.3 \mathrm{~m}$. Hence according to Scenario A, the model would 

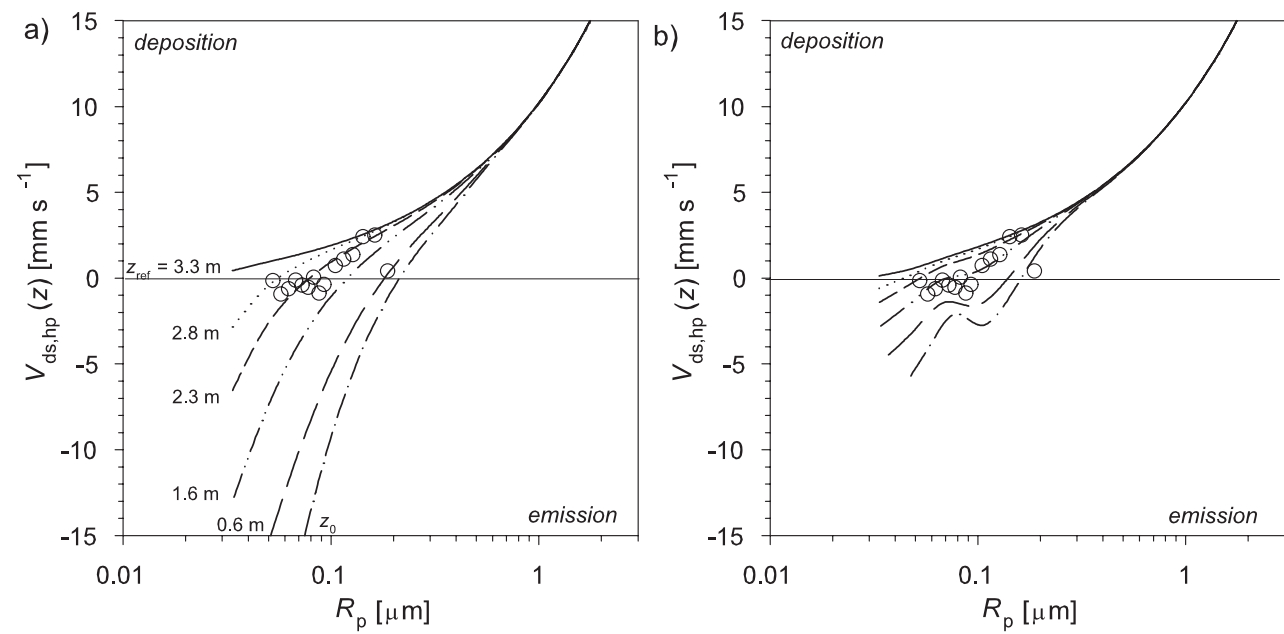

Fig. 12. Model output for 5 June, 13:00 GMT using Scenario D: apparent particle deposition velocity for (a) hydrophilic aerosol and (b) total aerosol as a function of particle radius $\left(R_{\mathrm{p}}\right)$ and height $(z)$. The parameterization of $V_{\mathrm{ds} \text {,inert }}$ is according to Eq. (12) of Nemitz et al. (2004b); $\alpha=1$. Circles $(\bigcirc)$ represent $V_{\text {ds }}$ derived from eddy-correlation flux measurements at $z=2.65 \mathrm{~m}$ (Nemitz et al., $2004 \mathrm{~b}$ ).

suggest the true surface uptake resistances of $\mathrm{HNO}_{3}$ to be even larger than derived with the aerodynamic gradient technique (Nemitz et al., 2004a).

\subsection{Apparent aerosol emission by particle evaporation (fol-} lowing Scenario D)

According to Scenario D, thermodynamic equilibrium was assumed to be attained well above the ground, and for convenience this is applied here at the upper measurement height $(z=3.3 \mathrm{~m})$. Figure 11 shows the results for the bulk species during the example run for this scenario. The large value of $\alpha=1$ that best fits the measurements leads to relative short chemical time-scales of about $6 \mathrm{~min}$ as well as flux reversal for the $\mathrm{NH}_{4} \mathrm{NO}_{3}$ flux. Near the corresponding height the concentration is at a minimum and $\tau_{\mathrm{c}}$ therefore shows a maximum. In Fig. 12a the values of $V_{\mathrm{ds}, \mathrm{hp}}$ derived by the model are compared with the measured values, with good agreement at $z_{\text {meas }}$, while the values predicted for the total aerosol $\left(V_{\mathrm{ds}, \bmod }\right.$; Fig. $\left.12 \mathrm{~b}\right)$ underestimate the measurements. In this model run, although equilibrium is assumed to hold at a height of $3.3 \mathrm{~m}$, concentrations at this height are probably still affected by the deposition process. Concentrations might not reach the equilibrium value even if extrapolated to a height of $50 \mathrm{~m}$ (Nemitz, 1998), bearing in mind that the exact thermodynamic value is difficult to estimate. If equilibrium is attained at a higher height, the departure from equilibrium would be larger over the height range of the measurements and a smaller, and possibly more realistic, value in $\alpha$ would be sufficient to fit the measurements.

The diurnal courses of $V_{\mathrm{ds} \text {,mod }}$ modelled for 5 June according to Scenario D for the surface $\left(z_{0}\right)$ are presented in Fig. 13, as the effect on $V_{\mathrm{ds}}$ measurements at the $z_{\text {meas }}$ turns out to be small. Two reasons can be identified: a large fraction of the aerosol is assumed to be hydrophobic ( $f_{\mathrm{hp}}$ small), thus re- mains unaffected by the chemical conversion and deposits at $V_{\mathrm{ds} \text {,inert }}$. As a result $V_{\mathrm{dp}, \mathrm{hp}}$ contributes only slightly to the modelled $V_{\mathrm{ds}, \text { mod }}$ for the total aerosol. In addition, since the $z_{\text {meas }}(2.65 \mathrm{~m})$ is very close to the chosen $z_{\text {eq }}(3.3 \mathrm{~m})$ the divergence from equilibrium at this height is not large enough to cause substantial flux divergence. If the scenario that equilibrium is attained well above the surface is correct, $z_{e q}$ is almost certainly very much larger than $3.3 \mathrm{~m}$, while $f_{\mathrm{hp}}$ is quite possibly underestimated. Hence the effect of aerosol evaporation on the $V_{\mathrm{ds} \text {,hp }}$ measurements at $2.65 \mathrm{~m}$ may in fact be as large as predicted for $z_{0}$ by the current model.

Although some features of the measurements are not reproduced by the model, the overall pattern is similar. The $V_{\mathrm{ds}, \text { hp }}$ of the largest size class $\left(R_{\mathrm{p}}\right.$ about $\left.0.12 \mu \mathrm{m}\right)$ remains largely unaffected by aerosol evaporation, while for the middle size class the deposition velocity is reduced in the afternoon. During this period the effect of aerosol evaporation is large enough for the smallest particles $\left(R_{\mathrm{p}}=0.05 \mu \mathrm{m}\right)$ to show apparent emission. The relative difference of the surface exchange fluxes of $\mathrm{HNO}_{3}$ and $\mathrm{NH}_{3}$ between $z=3.3 \mathrm{~m}$ and $z_{0}$ is on average 8.5 and $28 \%$, respectively. Consistent with aerosol evaporation, gas deposition fluxes are underestimated at $3.3 \mathrm{~m}$, which can partly, but not fully, explain the magnitude and consistency of the apparent surface uptake resistance of $\mathrm{HNO}_{3}$ found at Elspeet (Nemitz et al., 2004a).

\section{Discussion}

\subsection{Theoretical model assessment}

The time-evolution of aerosol size-spectra as modified by condensation and evaporation has been the subject of various modelling studies (e.g. Dahlin et al., 1981; Harrison et al., 1990; Bai et al., 1995; Kerminen and Wexler, 1995; 


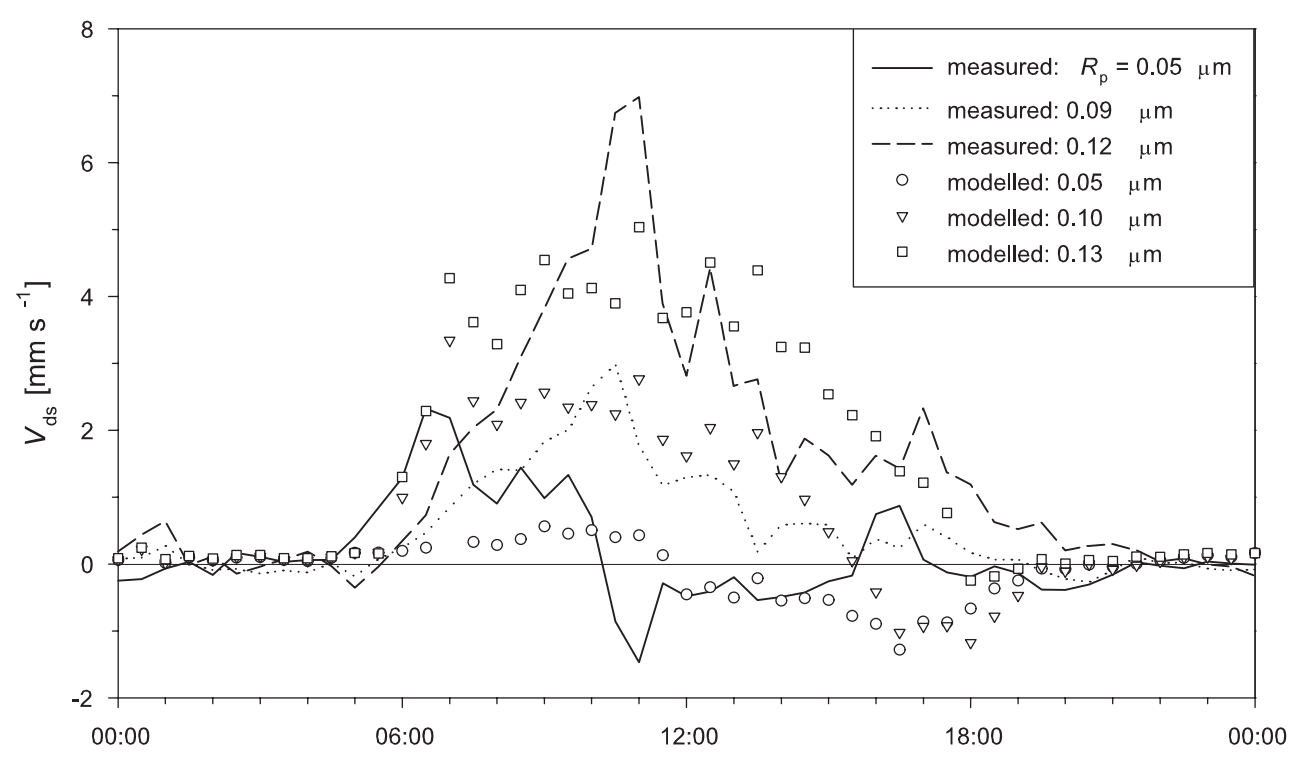

Fig. 13. Same as Fig. 10, but for Scenario $\mathrm{D}$ and $\alpha=1 . V_{\mathrm{ds}}$ is presented as derived from the fluxes at $z_{0}$, as the model leads to small effects for the height of the ultrasonic anemometer $(2.65 \mathrm{~m})$, most likely due to an underestimation of $z_{\mathrm{eq}}=3.3 \mathrm{~m}$ (see text).

Kulmala et al., 1995; Dhaniyala and Wexler, 1996; Meng and Seinfeld, 1996; Kerminen et al., 1997; Makar et al., 1998). However, these models have hardly ever been coupled with surface/atmosphere exchange processes. Here a 1-D model is presented that solves the steady state equations of the vertical profiles of differently sized particles as modified by the $\mathrm{HNO}_{3}-\mathrm{NH}_{3}-\mathrm{NH}_{4} \mathrm{NO}_{3}$ system and therefore explicitly predicts the height dependence of the $\mathrm{NH}_{4} \mathrm{NO}_{3}$ sizedistribution, together with the vertical profiles of the concentrations and fluxes of the bulk concentrations of $\mathrm{HNO}_{3}, \mathrm{NH}_{3}$ and $\mathrm{NH}_{4} \mathrm{NO}_{3}$. This model obeys mass conservation and is consistent with the model for the bulk species, except for the Kelvin effect and the effect of size-dependent particle composition on the gas equilibrium partial pressures of aqueous aerosol, which cannot be accounted for in the bulk model.

Application of the model to a log-normal distribution of pure $\mathrm{NH}_{4} \mathrm{NO}_{3}$ shows that the perturbation of the equilibrium of the $\mathrm{HNO}_{3}-\mathrm{NH}_{3}-\mathrm{NH}_{4} \mathrm{NO}_{3}$ system due to deposition and emission processes leads to size-dependent divergence of $V_{\mathrm{ds}}$ as it would be derived from EC measurements for submicron particles. The direction of the effect is dependent on the height at which equilibrium is attained. While gtpc $\left(K_{\mathrm{m}}>K_{\mathrm{e}}\right)$ leads to apparent reduced $V_{\mathrm{ds}}$ or emission if $z_{\mathrm{eq}}$ is lower than $z_{\text {meas }}$ (Scenario A), enhanced deposition is found if $z_{\text {eq }}$ is higher than $z_{\text {meas }}$ (Scenario B). By contrast, during aerosol evaporation $\left(K_{\mathrm{m}}<K_{\mathrm{e}}\right), V_{\mathrm{ds}}$ would seem raised below $z_{\text {eq }}$ (Scenario C) and underestimated above $z_{\text {eq }}$ (Scenario D). As a result, apparent emission of small particles may be found for $K_{\mathrm{m}}>K_{\mathrm{e}}$ above $z_{\mathrm{eq}}$ as well as for $K_{\mathrm{m}}<K_{\mathrm{e}}$ below $z_{\mathrm{eq}}$ (Scenarios $\mathrm{A}$ and $\mathrm{D}$, respectively). Bearing in mind that the model neglects new particle formation and only treats particle growth or evaporation, physically, particle deposition has to occur at the surface $\left(z_{0}\right)$ across all size ranges at a rate given by the deposition velocity for inert tracers and the concentration at $z_{0}$. Observations of deviation from this value are an effect due to condensational particle growth or evaporation (Eq. 9) and apparent $\mathrm{NH}_{4} \mathrm{NO}_{3}$ emission at $z_{0}$ may arise for certain size-classes as a change of the particle composition with height.

The magnitude of the effect and in particular the particle radius at which the flux changes from deposition to emission depends on the deviation of the concentrations from equilibrium, the sticking coefficient $(\alpha)$, the parameterization of $V_{\mathrm{ds} \text {,inert }}$ (Fig. 5) and the shape of the aerosol size-distribution, but for the application to measurement data it is also crucially dependent on the height of $z_{\mathrm{eq}}$, as well as the fraction of the aerosol affected by the chemistry $\left(f_{\mathrm{hp}}\right)$.

\subsection{Model application to measurement data}

Problems in the accurate prediction of $K_{\mathrm{e}}$ from thermodynamic theory make it difficult to decide conclusively whether for given measurement periods at Elspeet $K_{\mathrm{m}}>K_{\mathrm{e}}$ or $K_{\mathrm{m}}<K_{\mathrm{e}}$. Taking the vertical gradients of $T$ and $h$ into account, the relative magnitude of measured profiles of $K_{\mathrm{m}}$ and predicted profiles of $K_{\mathrm{e}}$ are consistent with Scenarios A and D, and contradict Scenarios B and C (Fig. 7). The observation of the size-dependent bi-directional particle fluxes at Elspeet therefore agrees well with the effects expected from the $\mathrm{NH}_{3}-\mathrm{HNO}_{3}-\mathrm{NH}_{4} \mathrm{NO}_{3}$ chemistry.

The model application to data obtained during an example run demonstrates that both Scenarios (A and D) are capable of predicting values of $V_{\mathrm{ds} \text {, mod }}$, similar to the measurements (Figs. 9 and 12). In both cases, the small values of $f_{\mathrm{hp}}$ lead 
to $V_{\mathrm{ds} \text {, mod }}$ to be very different from $V_{\mathrm{ds}, \mathrm{hp}}$, emphasizing the sensitivity of $V_{\mathrm{ds} \text {, mod }}$ to the choice of $V_{\mathrm{ds} \text {, inert }}$ and $f_{\mathrm{hp}}$, both of which are rather uncertain. In addition, hydrophilic aerosol is assumed to be composed only of the measured ionic aerosol species, while hydrophilic and hydrophobic aerosol species are assumed in the model not to co-exist within the same particles. These simplifications may constitute an underestimation of the aerosol fraction available for the reaction, resulting in an overestimation of $\tau_{\mathrm{c}}$ and underestimation of the effect on $V_{\mathrm{ds} \text {,mod. }}$. In the light of these uncertainties, the agreement between the diurnal courses of modelled and measured particle $V_{\mathrm{ds}}$ of three example size-classes (Figs. 10 and 13) is satisfactory and supports the theory that the apparent emission of fine particles was caused by gtpc/evaporation effects. In particular, the model correctly predicts emission to be observed in the afternoon, although individual features in the measurements are not well reproduced.

On the whole the model approach using Scenario D shows the better agreement. For this approach the measured values are compared with $V_{\mathrm{ds} \text {, mod }}$ predicted for $z_{0}$, which are most heavily influenced by aerosol evaporation, rather than for the measurement height. The choice of a larger $z_{\mathrm{eq}}$ would greatly increase the effect at the measurement height; it is very likely that the concentrations at $z=3.3 \mathrm{~m}$ were still affected by the deposition process and that the departure from equilibrium has been artificially decreased in the model application.

As discussed by Nemitz (1998) $K_{\mathrm{m}}$ estimated for $z=50 \mathrm{~m}$ was closer to $K_{\mathrm{e}}$ than derived for $z-d=1 \mathrm{~m}$, while the largest deviation $\left(K_{\mathrm{m}}<K_{\mathrm{e}}\right)$ was found at $z_{0}$. Bearing in mind that the extrapolation was done under the assumption that the concentration profiles are unaffected by gtpc/aerosol evaporation and that the constant flux layer extended to this height (i.e. approximately log-linear profiles with the gradient modified only by effects of atmospheric stability as $\mathrm{d} \chi / \mathrm{d}[\ln (z)-\Psi(z / L)])$, this nevertheless indicates that $z_{\mathrm{eq}}$ may have been of the order of tens of metres and that Scenario D reflects the conditions at Elspeet better than Scenario A. In addition, the observation of $V_{\mathrm{d}} \ll V_{\max }$ for $\mathrm{HNO}_{3}$ (Nemitz et al., 2004a) and large values of $V_{\mathrm{ds}}\left(\mathrm{NH}_{4}^{+}\right)$from gradient measurements (Nemitz et al., 2004b) are also in agreement with aerosol evaporation, while gtpc should lead to the observation of enhanced deposition rates of acids and reduced deposition rates of $\mathrm{NH}_{4}^{+}$. These observations therefore offer further support of Scenario D. The average difference in the $\mathrm{HNO}_{3}$ flux between the $z_{0}$ and the measurement height of $8.5 \%$ is, however, not sufficient to explain fully the observed reduction of $V_{\mathrm{d}}$ compared with $V_{\max }$, which was on average $44 \%$ for dry daytime conditions (Nemitz et al., 2004a, Table 3). This indicates that the significant canopy uptake resistance $\left(R_{\mathrm{c}}\right)$ observed for $\mathrm{HNO}_{3}$ is a real feature of the exchange process, quite possibly caused by the evaporation of $\mathrm{NH}_{4} \mathrm{NO}_{3}$ from leaf surfaces. Nemitz et al. (2004b) draw together all the evidence for aerosol evaporation and find good temporal correlation of the anomalous fluxes observed.
5.3 Uncertainties and recommendations for further investigations

The higher complexity of the present model compared with the bulk models (e.g. Brost et al., 1988; Kramm and Dlugi, 1994) results in an increased number of input parameters. At Elspeet an extensive dataset of simultaneous gradient measurements and aerosol characterization was obtained, but some key parameters still remain uncertain:

a) Insufficient knowledge of the size-dependent aerosol composition, especially of particles with $R_{\mathrm{p}}<0.125 \mu \mathrm{m}$ and as a function of time, leads to uncertainties in the estimate of the aerosol available for the reaction in relation to the $\mathrm{NH}_{4} \mathrm{NO}_{3}$ concentration and the number distribution of the total aerosol, expressed through $S_{i h}$ and $f_{\mathrm{hp}}$, respectively.

b) In common with all current parameterizations of $V_{\mathrm{ds}}$ for inert aerosol $\left(V_{\mathrm{ds} \text {,inert }}\right)$ as a function of particle size, the parameterization used here Eq. (12) of Nemitz et al. (2004b) has some deficiencies and leads to negative values for very fine aerosol.

c) The equilibrium height $\left(z_{\text {eq }}\right)$ is currently unknown and measurements in the surface layer $(0-4 \mathrm{~m})$ should ideally be complemented by parallel measurements at larger heights $(20-50 \mathrm{~m})$, which would be less affected by surface / atmosphere exchange processes and may also provide a measurement of $K_{\mathrm{e}}$.

d) Operationally, the current model requires equilibrium to be attained within the height-range of the model. For this reason equilibrium had to be assumed at a comparably low height of $z_{\text {ref }}=3.3 \mathrm{~m}$ for Scenarios B and D. Extension of concentration measurement to larger heights would provide input parameters for more realistic model runs under these conditions.

These add to the general uncertainties currently associated with the modelling of gtpc/aerosol evaporation on surface exchange fluxes, which include:

e) The prediction of the gas concentration products in equilibrium with the aerosol phase $\left(K_{\mathrm{e}}\right)$.

f) The reaction mechanism, time-scale and in particular the sticking coefficient $(\alpha)$.

g) The role of competing reactions such as the $\mathrm{NH}_{3}-\mathrm{HCl}-$ $\mathrm{NH}_{4} \mathrm{Cl}$ system and the interaction between $\mathrm{NH}_{3}$ and $\mathrm{SO}_{2}$.

Further uncertainty is introduced by the fact that the particle sizers (APS and SMPS) infer the mobility diameter, while the ASASP-x detects the optical diameter, which varies with the refractive index of the particles (e.g. Garvey and Pinnick, 1983), and atmospheric particles are in general not spherical. 
The model predicts the effects of gtpc/aerosol evaporation to be even more substantial for the $V_{\mathrm{ds}}$ of particles smaller than the lower cut-off radius of the ASASP-X $\left(R_{\mathrm{p}}<0.05 \mu \mathrm{m}\right)$, which would show up in respective flux measurements. Since these small particles cannot currently be sized by optical methods, the application of multiple Differential Mobility Analyzers (DMA) in gradient configuration may provide a useful tool for the validation of the modelled processes.

At Elspeet the chemical composition of the particles showing apparent upward fluxes was not explicitly identified. Since these small particles carry only little mass, it is very difficult to prove that the particle growth/evaporation is due to the $\mathrm{HNO}_{3}-\mathrm{NH}_{3}-\mathrm{NH}_{4} \mathrm{NO}_{3}$ system. At the moment the model results only show that this kind of gas-particle interaction is capable of causing the observed bi-directional fluxes, but other gtpc/aerosol processes such as the photochemical heterogeneous oxidation of (biogenic) volatile and biogenic (semi-)volatile organic compounds (BVOC's) may be an additional explanation. Nevertheless, many physical processes considered in this model, including the size-dependency of the chemical time-scale, are generic to heterogeneous reactions. As a result, the size-segregated effect on the EC measurement of $V_{\mathrm{ds}}$ should be similar, independent of the actual chemical reaction. New instrumentation for the measurement of speciated size-distributions at high temporal resolution (e.g. Jayne et al., 2000) will help provide improved aerosol information for future studies and may form the basis for eddy-covariance measurements of size and composition distributed aerosols.

In this study surface/atmosphere exchange fluxes of the chemical species were derived from measurements of concentration gradients. For a full and independent validation of the model predictions, it would be necessary to measure the fluxes of the individual chemical species $\left(\mathrm{NH}_{3}, \mathrm{HNO}_{3}\right.$ and size-segregated $\mathrm{NH}_{4} \mathrm{NO}_{3}$ ) at several heights to quantify the vertical flux divergence directly. Eddy-covariance and (relaxed) eddy accumulation approaches needed for these measurements have only just begun to be extended to these reactive compounds, and it is unlikely that they will become sufficiently accurate to derive flux gradients of often $<10 \%$ in the near future.

\subsection{Quantification of the effect of gpic on net exchange fluxes of $\mathrm{NH}_{3}, \mathrm{HNO}_{3}$ and $\mathrm{NH}_{4} \mathrm{NO}_{3}$}

On the example day of 5 June, the equivalent concentrations followed $\chi \mathrm{NH}_{4} \mathrm{NO}_{3} \ll \chi \mathrm{HNO}_{3}<\chi_{\mathrm{NH}_{3}}$ during daytime, while $\chi_{\mathrm{HNO}_{3}}$ was much smaller during the night. Although $V_{\mathrm{d}}\left(\mathrm{HNO}_{3}\right)<V_{\max }\left(\mathrm{HNO}_{3}\right)$ during the day, the deposition flux of $\mathrm{HNO}_{3}$ was considerably larger than $F\left(\mathrm{NH}_{3}\right)$, which was small, switching between deposition and emission. Consequently, the relative difference in $F\left(\mathrm{NH}_{3}\right)$ between $z=3.3 \mathrm{~m}$ and $z_{0}$ of $-10 \%$ was on average larger magnitude than for the value of $-5.2 \%$ found for $\mathrm{HNO}_{3}$ for Scenario A us- ing $\alpha=0.05$. Conversely, $F\left(\mathrm{NH}_{3}\right)$ changed by $+28 \%$ and $F\left(\mathrm{HNO}_{3}\right)$ by $+8.5 \%$ following Scenario D with $\alpha=1$. These results are in broad agreement with the first estimate of the effect derived by Nemitz et al. (2004b). Although Scenario D leads to a reduced $V_{\mathrm{d}}\left(\mathrm{HNO}_{3}\right)$ at the measurement height if compared with $V_{\mathrm{d}}\left(z_{0}\right)$, the difference is not sufficient to explain the divergence from $V_{\max }$ completely. As discussed above, $z_{\text {eq }}$ but also $f_{\text {hp }}$ were probably underestimated and the flux divergence may have been larger. The model presented here only accounts for the evaporation potential of airborne $\mathrm{NH}_{4} \mathrm{NO}_{3}$. It is likely that $\mathrm{NH}_{4} \mathrm{NO}_{3}$ is also present on leaf surfaces, either from previously deposited particles or as a consequence of co-deposition of $\mathrm{NH}_{3}$ and $\mathrm{HNO}_{3}$ which may form $\mathrm{NH}_{4} \mathrm{NO}_{3}$ particles attached to leaves when leaf water-layers evaporate. Such surface $\mathrm{NH}_{4} \mathrm{NO}_{3}$ would result in a non-zero surface concentration of $\mathrm{HNO}_{3}$, raising the surface resistance. Hence, although aerosol evaporation can in part explain observations of $V_{\mathrm{d}}\left(\mathrm{HNO}_{3}\right)<V_{\max }$ (Harrison et al., 1989; Sutton et al., 1993), the data here point to nonzero $R_{\mathrm{c}}\left(\mathrm{HNO}_{3}\right)$ as being a real phenomenon under conditions favouring $\mathrm{NH}_{4} \mathrm{NO}_{3}$ evaporation from canopy surfaces.

Over the height range of the measurements, flux reversal occurred occasionally for $\mathrm{NH}_{3}$ and more often for $\mathrm{NH}_{4} \mathrm{NO}_{3}$ (Figs. 8 and 11). In agreement with the EC measurements, the model predicts the observation of apparent emission of small particles. This potentially leads to a significant underestimation of $V_{\mathrm{d} \text {,inert }}$ if parameterized from EC measurements affected by gtpc/aerosol evaporation processes and may therefore have implications for the (under-) estimation of aerosol dry deposition.

As mentioned in the Introduction, apparent aerosol emission of small fluxes was observed during a joint BIATEX field campaign in April/May 1991 at the Dutch heathland "Leende Heide" (Fig. 1). For the same campaign Zhang et al. (1995) reported upward gradients of $\mathrm{HNO}_{3}$ and $K_{\mathrm{m}}<K_{\mathrm{e}}$ for afternoon periods, in agreement with $\mathrm{NH}_{4} \mathrm{NO}_{3}$ evaporation. These authors also presented a first-order correction of the $\mathrm{NH}_{3}$ flux of up to $-100 \mathrm{ng} \mathrm{m}^{-2} \mathrm{~s}^{-1}$ under the assumption that at the surface $\mathrm{HNO}_{3}$ was deposited at $V_{\text {max }}$. Inconsistencies arose during night, when the upward gradients of $\mathrm{HNO}_{3}$ continued despite the observation of $K_{\mathrm{m}}>K_{\mathrm{e}}$. Nevertheless, the similarity of the observations indicates that aerosol evaporation may have a large effect on gas and aerosol fluxes at semi-natural sites across the Netherlands. High emissions of $\mathrm{NH}_{3}$ from agricultural activities suppress $\mathrm{HNO}_{3}$ concentrations and result in large $\mathrm{NH}_{4} \mathrm{NO}_{3}$ concentrations (e.g. ten Brink et al., 1996). Above semi-natural vegetation, deposition of $\mathrm{HNO}_{3}$ and usually $\mathrm{NH}_{3}$ leads to the potential for aerosol evaporation, especially over warm canopies during the day. Given the high aerosol concentrations, there is plenty of $\mathrm{NH}_{4} \mathrm{NO}_{3}$ to evaporate and chemical time-scales are often short enough for flux divergence to be significant.

In addition to gpic having the potential to cause artefacts in flux measurements, it should also be noted that gpic may also modify the net exchange of total $\mathrm{NH}_{\mathrm{x}}$ and $\mathrm{NO}_{\mathrm{y}}$. It has 
been pointed out that gpic only requires measurement corrections to the component gas and aerosol fluxes, while the flux of total gastaerosol flux (i.e. of TN and TA) is conserved. However, importantly, gpic changes the partitioning between gas and aerosol, which have contrasting values of $V_{\mathrm{d}}$, and gpic therefore modifies the total gas+aerosol flux compared with a situation without chemical conversion. This may be illustrated in the present case according to Scenario D (aerosol evaporation: $K_{\mathrm{m}}<K_{\mathrm{e}}, z_{\text {eq }}>z_{\text {meas }} \mathrm{NH}_{3}$ deposition), where at the surface $V_{\mathrm{d}}\left(\mathrm{NH}_{3}, \mathrm{HNO}_{3}\right)>V_{\mathrm{d}}$ (aerosol). Evaporation of the aerosol provides additional $\mathrm{NH}_{3}$ and $\mathrm{HNO}_{3}$ near the ground, facilitating a net increase in total $\mathrm{N}$ deposition. Conversely, in the case of Scenario B (gpc: $K_{\mathrm{m}}>K_{\mathrm{e}}$, $z_{\text {eq }}>z_{\text {meas }}, \mathrm{NH}_{3}$ emission), gradient measurements might appear to show $V_{\mathrm{d}}\left(\mathrm{HNO}_{3}\right) \geq V_{\max }$ (Sutton et al., 1993). However, here, aerosols rather than the canopy surface represent part of the sink for the $\mathrm{HNO}_{3}$, which having a smaller $V_{\mathrm{d}}$ than $\mathrm{HNO}_{3}$ reduces the overall $\mathrm{N}$ deposition. The general consequence of this interaction is therefore a tendency to reduce deposition in $\mathrm{NH}_{3}$ source areas, while increasing deposition to areas that are already sinks for $\mathrm{NH}_{3}$.

\section{Conclusions}

Theoretical investigations using the present model demonstrate that the heterogeneous chemistry of the $\mathrm{NH}_{3}-\mathrm{HNO}_{3}-$ $\mathrm{NH}_{4} \mathrm{NO}_{3}$ system is probably responsible for the observation of simultaneous emission of small particles and deposition of larger particles, repeatedly made during eddy-covariance (EC) particle flux measurements above semi-natural vegetation. Two possible situations have been identified: i) gas-toparticle conversion (gtpc) at $K_{\mathrm{m}}>K_{\mathrm{e}}$ causes apparent emission of small particles at heights above the height at which thermodynamic equilibrium is attained $\left(z_{\text {eq }}\right)$ and this situation may arise during advection of either $\mathrm{NH}_{3}$ or $\mathrm{HNO}_{3}$; ii) aerosol evaporation at $K_{\mathrm{m}}<K_{\mathrm{e}}$ causes evaporation of aerosol below $z_{\text {eq }}$, leading to apparent emissions of fine particles, which is consistent with equilibrium in the higher atmosphere and $\mathrm{HNO}_{3}$ deposition, and may be enhanced by $\mathrm{NH}_{3}$ deposition and high canopy temperatures.

The application of the two model scenarios to measurement data from Elspeet reveals that either process may be responsible for the simultaneous emission of small particles $\left(R_{\mathrm{p}}<0.10 \mu \mathrm{m}\right)$ and deposition of larger particles measured by EC at Elspeet and during other studies. However, the somewhat better model fit of the second approach, together with better agreement of the extrapolated concentrations with thermodynamic equilibrium at higher heights, as well as the observation of reduced $\mathrm{HNO}_{3}$ and fast $\mathrm{NH}_{4}^{+}$deposition by gradient technique, suggest that the negative values of aerosol $V_{\mathrm{ds}}$ were caused by aerosol evaporation during the deposition process (i.e. explanation ii.). The flux measurements of larger particles remain unaffected by gtpc/aerosol evaporation, because the mass flux to and from these par- ticles is subject to long characteristic times and leads to a much smaller relative change in particle size than for small particles. Some uncertainties remain due to the limited sizesegregation and temporal resolution of the measured size distribution and composition of the aerosol. At present it cannot be ruled out that other heterogeneous reactions such as the photochemical oxidation of BVOCs (also) affected the flux measurements, although the physical processes should be similar.

Even if the relative effect on the gas fluxes is relatively small $(<10 \%)$, the effect of gtpc/aerosol evaporation on sizesegregated particle flux measurements can be large, potentially contaminating the parameterizations derived from EC particle flux measurements as well as gradient measurements of $\mathrm{HNO}_{3}$ and $\mathrm{NH}_{3}$ fluxes. The application of these parameterizations to aerosol components not involved in the reactions, such as $\mathrm{Na}^{+}, \mathrm{SO}_{4}^{2-}$ and heavy metals, may lead to a significant underestimation of their deposition. In deriving $V_{\mathrm{ds}}$ from field measurements extra care should therefore be taken to ensure that gas-to-particle conversion and aerosol evaporation do not affect the measurements. On a more positive note, the investigations imply that size-segregated particle number flux measurements provide a means to estimate whether gtpc and evaporation processes are likely to contaminate the flux measurements of $\mathrm{NH}_{3}, \mathrm{HNO}_{3}$ and $\mathrm{HCl}$ and to quantify conversion rates.

\section{Appendix A}

This appendix introduces the logarithmic height co-ordinate and derives the central differential Eq. (11). Given the logarithmic concentration profiles, in the model differential equations are generally integrated on a logarithmic height coordinate $(h)$ to improve the accuracy. Discrete height layers $\left(z_{h}\right)$ were defined for $h=1, \ldots, h_{\max }$ as (adapted from Kramm and Dlugi, 1994):

$$
z_{h}=\exp \left(\frac{h-1+b \ln \left(z_{0}\right)}{b}\right)
$$

with

$$
b=\frac{h_{\max }-1}{\ln \left(z_{\mathrm{ref}}\right)-\ln \left(z_{0}\right)} .
$$

Following the notation introduced in the main text, $c_{i h}$ represents the height-dependent $\mathrm{NH}_{4} \mathrm{NO}_{3}$ concentration in a certain size bin $(i)$. In the following the indices $i$ and $h$ are dropped and the operator ${ }^{\prime}$ is used for the total derivative with respect to $h(\mathrm{~d} / \mathrm{d} h)$. From the relationship between $h$ and the physical height (z), Eq. (A1), the first derivative of $c$ with respect to $h\left(c^{\prime}\right)$ is related to the $\mathrm{d} c / \mathrm{d} z$ by:

$c^{\prime}=\frac{\partial z}{\partial h} \frac{\mathrm{d} c}{\mathrm{~d} z}=\frac{z}{b} \frac{\mathrm{d} c}{\mathrm{~d} z}$ 
Similarly, the second derivative $\left(c^{\prime \prime}\right)$ is given by

$c^{\prime \prime}=\frac{\mathrm{d}}{\mathrm{d} h}\left(\frac{z}{b}\right) \frac{\mathrm{d} c}{\mathrm{~d} z}+\left(\frac{z}{b}\right)^{2} \frac{\mathrm{d}^{2} c}{\mathrm{~d} z^{2}}=\frac{c^{\prime}}{b}+\left(\frac{z}{b}\right)^{2} \frac{\mathrm{d}^{2} c}{\mathrm{~d} z^{2}}$.

The model is based on first-order relaxation towards equilibrium (Eq. 1) and first-order closure through the classical flux-gradient relationship for inert tracers (Eq. 3). From these equations the second-order derivative of $c$ with respect to $z$ may be derived as:

$$
\begin{aligned}
\frac{\mathrm{d}^{2} c}{\mathrm{~d} z^{2}} & =-\frac{1}{K_{\mathrm{H}}} \frac{\mathrm{d} F}{\mathrm{~d} z}+\frac{F}{K_{\mathrm{H}}^{2}} \frac{\mathrm{d} K_{\mathrm{H}}}{\mathrm{d} z} \\
& =\frac{1}{K_{\mathrm{H}}} \frac{c_{\mathrm{tot}, i}-c_{\mathrm{tot}, i, \mathrm{eq}}}{\tau_{\mathrm{c}, i h}}+\frac{\beta^{2} c^{\prime} K_{\mathrm{H}}^{\prime}}{z^{2} K_{\mathrm{H}}}
\end{aligned}
$$

and this equation may be substituted into Eq. (A4).

By analogy with Eq. (9) the change in the radius with $h$ can be calculated from the change in the concentration and the number density from Eq. (8):

$$
R^{\prime}=\frac{\partial R}{\partial c} c^{\prime}+\frac{\partial R}{\partial n} n^{\prime}=\frac{c^{\prime}}{3 k R^{2} n}-\frac{c n^{\prime}}{3 k R^{2} n^{2}}
$$

Forming the second derivative of $R$ with respect to $h\left(R^{\prime \prime}\right)$ leads to

$$
\begin{aligned}
R^{\prime \prime}= & -\frac{c^{\prime} n^{\prime}}{3 k R^{2} n^{2}}-\frac{2 c^{\prime} R^{\prime}}{3 k R^{3} n}+\frac{c^{\prime \prime}}{3 k R^{2} n} \\
& -\frac{n^{\prime} c^{\prime}}{3 k R^{2} n^{2}}-\frac{c n^{\prime \prime}}{3 k R^{2} n^{2}}+\frac{2 c R^{\prime} n^{\prime}}{3 k R^{3} n^{2}}+\frac{2 c n^{2}}{3 k R^{2} n^{3}}
\end{aligned}
$$

in which $c^{\prime}$ and $c^{\prime \prime}$ can be substituted according to Eqs. (9) and (A4), respectively:

$$
\begin{aligned}
R^{\prime \prime}= & -\frac{2 R^{\prime} n^{\prime}}{n}-\frac{2 n^{\prime 2}}{3 n^{2}}\left(R-\frac{y}{R^{2}}\right)-\frac{2 R^{\prime 2}}{R} \\
& -\frac{2 R^{\prime} n^{\prime}}{3 n}\left(1-\frac{y}{R^{3}}\right)+\frac{R^{\prime}}{\beta}+\frac{n^{\prime}}{3 \beta n}\left(R-\frac{y}{R^{2}}\right) \\
& -\frac{K_{\mathrm{H}}^{\prime} R^{\prime}}{3 K_{\mathrm{H}}}-\frac{K_{\mathrm{H}}^{\prime} n^{\prime}}{3 K_{\mathrm{H}} n}\left(R-\frac{y}{R^{2}}\right)+\frac{2 c n^{\prime} R^{\prime}}{3 k n^{2} R^{2}} \\
& +\frac{2 c n^{\prime 2}}{3 k R^{2} n^{3}}-\frac{c n^{\prime \prime}}{3 k R^{2} n^{2}}+\frac{z^{2}\left(c_{\mathrm{tot}}-c_{\mathrm{tot}, \mathrm{eq}}\right)}{3 k K_{\mathrm{H}} \beta^{2} R^{2} n \tau_{\mathrm{c}}}
\end{aligned}
$$

Simplification of this expression yields Eq. (11).

Acknowledgements. This work was funded by the EU through the projects EXAMINE (EV5V-CT94-0426) and GRAMINAE (CT98-0722) and by the UK Department for Environment, Food and Rural Affairs (DEFRA) through the project "Acid Deposition Processes".

Edited by: M. Ammann

\section{References}

Andersen, H. V., Hovmand, M. F., Hummelshoj, P., and Jensen, N. O.: Measurements of ammonia concentrations, fluxes and dry deposition velocities to a spruce forest 1991-1995, Atmos. Environ., 33, 9, 1367-1383, 1999.

Bai, H., Lu, C., and Ling, Y. M.: A theoretical study on the evaporation of dry ammonium chloride and ammonium nitrate aerosols, Atmos. Environ., 29, 3, 313-321, 1995.

Brost, R. A., Delany, A. C., and Huebert, B. J.: Numerical Modeling of Concentrations and Fluxes of $\mathrm{HNO}_{3}, \mathrm{NH}_{3}$, and $\mathrm{NH}_{4} \mathrm{NO}_{3}$ near the Surface, J. Geophys. Res.-Atmos., 93, D6, 7137-7152, 1988.
Chamberlain, A. C.: Transport of gases to and from grass and grasslike surfaces, Proceedings of the Royal Society A, 290, 236-265, 1966.

Dahlin, R. S., Su, J.-A., and Peters, L. K.: Aerosol formation in reacting gases: theory and application to the anhydrous $\mathrm{NH}_{3}-\mathrm{HCl}$ system, American Institute of Chemical Engineering Journal, 27, 404-418, 1981.

Dassios, K. G. and Pandis, S. N.: The mass accommodation coefficient of ammonium nitrate aerosol, Atmos. Environ., 33, 18, 2993-3003, 1999.

Dhaniyala, S. and Wexler, A. S.: Numerical schemes to model condensation and evaporation of aerosols, Atmos. Environ., 30, 6, 919-928, 1996.

Dougle, P. G., Veefkind, J. P., and ten Brink, H. M.: Crystallization of mixtures of ammonium nitrate, ammonium sulphate and soot, J. Aeros. Sci., 29, 3, 375-386, 1998.

Duyzer, J. H., Deinum, G., and Baak, J.: The interpretation of measurements of surface exchange of nitrogen oxides: corrections for chemical reactions, Philosophical Transactions of the Royal Society of London Series a - Mathematical Physical and Engineering Sciences, 351, 231-248, 1995.

Dzubay, T. G. and Hasan, H.: Fitting multimodal lognormal size distributions to cascade impactor data, Aerosol Science and Technology, 13, 144-150, 1990.

Fairall, C. W.: Interpretation of Eddy-Correlation Measurements of Particulate Deposition and Aerosol Flux, Atmos. Environ., 18, 7, 1329-1337, 1984.

Gallagher, M. W., Choularton, T. W., Wicks, A., Beswick, K. M., Coe, H., Sutton, M., Fowler, D., Duyzer, J. H., and Wyers, P.: Measurements of aerosol exchange to a Dutch heather moor, edited by Borrell, P. M., Borrell, P., Cavitas, T., and Seiler, W., In: Proceedings of the EUROTRAC Symposium' 92, GarmischPartenkirchen, Germany, SPB Academic Publishing b.v., The Hague, 694-698, 1993.

Gallagher, M. W., Beswick, K. M., Duyzer, J., Westrate, H., Choularton, T. W., and Hummelshoj, P.: Measurements of aerosol fluxes to Speulder forest using a micrometeorological technique, Atmos. Environ., 31, 3, 359-373, 1997.

Galmarini, S., Vila-Guerau de Arellano, J., and Duyzer, J.: Fluxes of chemically reactive species inferred from mean concentration measurements, Atmos. Environ., 31, 2371-2374, 1997.

Garland, J. A.: Dry Deposition of Sulfur-Dioxide to Land and Water Surfaces, Proceedings of the Royal Society of London Series a - Mathematical Physical and Engineering Sciences, 354, 1678, 245-268, 1977.

Garvey, D. M. and Pinnick, R. G.: Response characteristics of the Particle Measuring Systems Active Scattering Aerosol Spectrometer Probe (ASASP-X), Aerosol Science and Technology, 2, 477-488, 1983.

Harrison, R. M., Rapsomanikis, S., and Turnbull, A.: Land Surface Exchange in a Chemically-Reactive System - Surface Fluxes of $\mathrm{HNO}_{3}, \mathrm{HCl}$ and $\mathrm{NH}_{3}$, Atmos. Environ., 23, 8, 1795-1800, 1989.

Harrison, R. M., Sturges, W. T., Kitto, A. M. N., and Li, Y.: Kinetics of the evaporation of ammonium chloride and ammonium nitrate aerosols, Atmos. Environ., 24A, 7, 1883-1888, 1990.

Huebert, B. J., Luke, W. T., Delany, A. C., and Brost, R. A.: Measurements of Concentrations and Dry Surface Fluxes of Atmospheric Nitrates in the Presence of Ammonia, J. Geophys. Res.Atmos., 93, D6, 7127-7136, 1988. 
Jayne, J. T., Leard, D. C., Zhang, X., Davidovits, P., Smith, K. A., Kolb, C. E., and Worsnop, D. R.: Development of an aerosol mass spectrometer for size and composition analysis of submicron particles, Aerosol Science and Technology, 33, 49-70, 2000.

Keller, H. B.: Numerical methods for two-point boundary-value problems, Blaisdell, Waltham, Mass., USA, 184, 1968.

Kerminen, V.-M. and Wexler, A. S.: Growth laws for atmospheric particles: an examination of the bimodality of the accumulation mode, Atmos. Environ., 29, 22, 3263-3724, 1995.

Kerminen, V.-M., Wexler, A. S., and Potukuchi, S.: Growth of freshly nucleated particles in the troposphere: roles of $\mathrm{NH}_{3}$, $\mathrm{H}_{2} \mathrm{SO}_{4}, \mathrm{HNO}_{3}$ and $\mathrm{HCl}$, J. Geophys. Res.-Atmos., 102, 37153724, 1997.

Kowalski, A. S.: Deliquescence induces eddy covariance and estimable dry deposition errors, Atmos. Environ., 35, 28, 48434851, 2001.

Kramm, G. and Dlugi, R.: Modelling of the vertical fluxes of nitric acid, ammonia and ammonium nitrate, J. Atmos. Chem., 319357, 1994.

Kulmala, M., Mäkelä, J. M., Choularton, T. W., Wiedensohler, A., and Hansson, H. C.: Formation of ammonium chloride particles from hydrogen chloride and ammonia, J. Aeros. Sci., 26 (Suppl. 1), S463-S464, 1995.

Makar, P. A., Wiebe, H. A., Staebler, R. M., Li, S.-M., and Anlauf, K.: Measurement and modelling of particle nitrate formation, J. Geophys. Res.-Atmos., 103, D11, 13 095-13 110, 1998.

Meng, Z. and Seinfeld, J. H.: Time scales to achieve atmospheric gas-aeorsol equilibrium for volatile species, Atmos. Environ., 30, 2889-2900, 1996.

Mozurkewich, M.: The dissociation constant of ammonium nitrate and its dependence on temperature, relative humidity and particle size, Atmos. Environ., 27, 261-270, 1993.

Nemitz, E. G.: Surface/atmosphere exchange of ammonia and chemically interacting species, Ph.D. Thesis, UMIST, Manchester, UK, 302, 1998.

Nemitz, E., Sutton, M. A., Fowler, D., and Choularton, T. W.: Application of a $\mathrm{NH}_{3}$ gas-to-particle conversion model to measurement data, edited by Sutton, M. A., Lee, D. S., Dollard, G., and Fowler, D., International conference on atmospheric ammonia, Institute of Terrestrial Ecology (ITE), Edinburgh, UK, Oxford, UK, 2-4 Oct. 1995, 98-103, 1996.

Nemitz, E., Fowler, D., McDonald, A. G., Theobald, M. R., Skiba, U., Gallagher, M. W., Dorsey, J. R., Bower, K. N., Beswick, K., Williams, P. I., and Erisman, J. W.: Recent advances in the quantification and parameterisation of the surface atmosphere exchange of atmospheric aerosols, Transport and Chemical Transformation in the Troposphere, edited by Midgley, P. M. and Reuther, M., Proceedings of EUROTRAC Symposium 2002, Garmisch-Partenkirchen, Germany, 11-15 March 2002, ISBN 38236-1385-5, Margraf Verlag, Weikersheim, Germany, 23-32, 2002.

Nemitz, E., Sutton, M. A., Wyers, G. P., and Jongejan, P. A. C.: Gas-particle interactions above a Dutch heathland: I. Surface exchange fluxes of $\mathrm{NH}_{3}, \mathrm{SO}_{2}, \mathrm{HNO}_{3}$ and $\mathrm{HCl}$, Atmos. Chem. Phys. Discuss., 4, 1473-1517, 2004a.

Nemitz, E., Sutton, M. A., Wyers, G. P., Otjes, R. P., Mennen, M. G., van Putten, E., Hellemond, J., and Gallagher, M. W.: Gasparticle interactions above a Dutch heathland: II. Concentrations and surface exchange fluxes of atmospheric particles, Atmos. Chem. Phys. Discuss., 4, 1519-1565, 2004b.

Press, W. H., Flannery, B. P., Teukolsky, S. A., and Vetterling, W. T.: Numerical recipes in Pascal - the art of scientific computing, Cambridge University Press, Cambridge, UK, 759, 1989.

Pryor, S. C., Barthelmie, R. J., Soerensen, L., and Jensen, B.: Ammonia concentrations and fluxes over a forest in the midwestern USA, Atmos. Environ., 35, 5645-5656, 2001.

Rattray, G. and Sievering, H.: Dry deposition of ammonia, nitric acid, ammonium, and nitrate to alpine tundra at Niwot Ridge, Colorado, Atmos. Environ., 35, 1105-1109, 2001.

Rudolf, R., Vrtala, A., Kulmala, M., Vesala, T., Viisanen, Y., and Wagner, P. E.: Experimental study of sticking probabilities for condensation of nitric acid - water vapor mixtures, Aerosol Science and Technology, 32, 913-932, 2001.

Schwartz, S. E. and Freiberg, J. E.: Mass-transport limitation to the rate of reaction of gases in liquid droplets - application to oxidation of $\mathrm{SO}_{2}$ in aqueous-solutions, Atmos. Environ., 15, 7, 1129-1144, 1981.

Seinfeld, J. H. and Pandis, S. N.: Atmospheric chemistry and physics, John Wiley \& Sons Inc, 1356, 1997.

Slinn, W. G. N.: Prediction for particle deposition to vegetative canopies, Atmos. Environ., 16, 7, 1785-1794, 1982.

Sutton, M. A., Pitcairn, C. E. R., and Fowler, D.: The Exchange of Ammonia between the Atmosphere and Plant-Communities, Advances in Ecological Research, 24, 301-393, 1993.

Sutton, M. A., Nemitz, E., Fowler, D., Wyers, G. P., Otjes, R., San Jose, R., Moreno, J., Schjoerring, J. K., Husted, S., Meixner, F. X., Ammann, C., Neftel, A., and Gut, A.: The EXAMINE Project: exchange of atmospheric ammonia with European ecosystems, Proceedings of Eurotrac'96, edited by Borrell, P. M., Borrell, P., Kelly, K., Cavitas, T., and Seiler, W., Computer Mechanics Publications, Southampton, Garmisch-Partenkirchen, 155-161, 1996.

Ten Brink, H. M., Veefkind, J. P., Waijers-Ijpelaan, A., and van der Hage, J. C.: Aerosol light-scattering in the Netherlands, Atmos. Environ., 30, 4251-4261, 1996.

Thom, A. S.: Momentum, mass and heat exchange, edited by Monteith, J. L., Vegetation and the atmosphere, Academic Press, Chichester, UK, 57-109, 1975.

Van Oss, R., Duyzer, J., and Wyers, P.: The influence of gas-toparticle conversion on measurements of ammonia exchange over forest, Atmos. Environ., 32, 3, 465-471, 1998.

Wexler, A. S. and Seinfeld, J. H.: The distribution of ammonium salts among size and composition dispersed aerosol, Atmos. Environ., 24A, 1231-1246, 1990.

Wexler, A. S. and Seinfeld, J. H.: Analysis of aerosol ammonium nitrate departures from equilibruim during SCAQS, Atmos. Environ., 26A, 579-591, 1992.

Wyers, G. P. and Duyzer, J. H.: Micrometeorological measurement of the dry deposition flux of sulphate and nitrate aerosols to coniferous forest, Atmos. Environ., 31, 3, 333-343, 1997.

Zhang, Y., ten Brink, H. M., Slanina, J., and Wyers, G. P.: The influence of ammonium nitrate equilibrium on the measurement of exchange fluxes of ammonia and nitric acid, Acid Rain Research: Do we have enough Answers?, edited by Heij, G. J. and Erisman, J. W., Elsevier Science B.V., 103-112, 1995. 